\title{
Fauna of Non-biting Midges (Diptera, Chironomidae) from Soyang River in Chuncheon-si, Gangwon-do, Korea
}

\author{
Han-II Ree ${ }^{1}$ and Kyoung Yong Jeong ${ }^{2, *}$ \\ 'Department of Environmental Medical Biology, and Institute of Tropical Medicine, \\ Yonsei University College of Medicine, Seoul 120-752, Korea \\ ${ }^{2}$ Department of Internal Medicine and Institute of Allergy, \\ Yonsei University College of Medicine, Seoul 120-752, Korea
}

\begin{abstract}
Adults of Chironomidae were collected at Soyang river sites in Chuncheon-si, Gangwon-do on 1 August and 14 September in 2008, and 1 May in 2009. A total of 794 adults were collected, consisting of 52 species, 23 genera, 4 subfamilies. Among them, 7 species were recorded in Korea for the first time, and 9 species were new to science. These 7 previously unrecorded and 9 new species are described with illustrations. Eight species still have not been identified. The subfamily Prodiamesinae and four genera: Demicryptochironomus, Parakiefferiella, Psectrocladius and Monodiamesa are the first record in Korea. Tanytarsus seohyoni n. sp. was the most dominant species, consisting of $24.6 \%$ of the total samples.
\end{abstract}

Keywords: Fauna, Chironomidae, Chuncheon-si, new species, taxonomy

\section{INTRODUCTION}

Non-biting midges live under the running or standing waters during egg, larva and pupa stage, and adult midges on earth for 2-7 days. Sometimes enormous amount of midges appear in areas close to human dwellings (Ree and Yum, 2006). Adult midges are attracted to light at night and cause serious nuisance to normal human activities. Furthermore, dead bodies of ephemeral midges can cause allergic disorders to the genetically predisposed individuals (Kay et al., 1978; Jeong et al., 2004). Non-biting midges are one of the most abundant and frequently encountered insects in Korea. Ninetyfour species have been described in Korea (Ree and Kim, 1981; Ree, 2009a, b), although at least several hundreds of species are expected to be found.

A large number of non-biting midges emerges throughout season (May-September) from the Soyang river which runs through Sinsau-dong, Chuncheon-si, where about 262,000 people live. These midges are regarded as one of the annoying insects in summer nights. In this study, taxonomical study of non-biting midges emerging from Soyang river in Chuncheon city was carried out.

\section{MATERIALS AND METHODS}

Chironomid adults attracted to lights of stores and restaurants

\footnotetext{
*To whom correspondence should be addressed

Tel: 82-2-2228-1840, Fax: 82-2-363-8676

E-mail: para@yuhs.ac
}

located close to Soyang river which runs through Sinsaudong, Chuncheon-si, Gangwon-do were aspirated for 2-3 hours after sunset on August 1 and September 9, 2008, and May 1, 2009, and kept in 75\% ethanol. Meadows are developed along with the riverside and sports facilities for the publics are located at the river bank. Many restaurants with good river-view are located in streets around Soyang bridge 1 (397 m). All midges were dissected into the antennae, head, wings, abdomen and hypopygium by using fine needles under stereomicroscope and mounted on Hoyer's solution. The type specimens of the new species are deposited in the collection of Arthropods of Medical Importance Resource Bank, Department of Environmental medical Biology, Yonsei Univeristy, Seoul, Korea.

\section{RESULTS}

\section{Faua of Chironomidae}

A total of 794 Chironomid adults were collected during the study period. They were identified as 4 subfamilies, 23 genera, 52 species (Table 1). Among 52 species, 7 species are recorded for the first time in Korea, and 9 species are new to science. Eight species have not yet been identified to species due to lack of references. Tanytarsus seohyoni n. sp. was the most dominant species in the study area, consisting of $24.6 \%$ of the total samples, followed by Tanytarsus akantertius Sasa and Kamimura (7.6\%), Paracladopelma camptolabis (Kieffer) 
Table 1. Adult collections of Chironomidae (Diptera) from Soyang river in Chuncheon, Gangwon-do, Korea on 1 August and 14 September in 2008 and 1 May in 2009.

\begin{tabular}{|c|c|c|c|c|c|}
\hline \multirow{2}{*}{ Species } & \multicolumn{5}{|c|}{ Number collected } \\
\hline & Aug. & Sept. & May & Total & $\%$ \\
\hline \multicolumn{6}{|l|}{ CHIRONOMINAE } \\
\hline \multicolumn{6}{|l|}{ CHIRONOMINI: } \\
\hline Chironomus flaviplumus & 3 & 1 & 8 & 12 & 1.5 \\
\hline Chironomus kiiensis & 5 & 8 & 0 & 13 & 1.6 \\
\hline Chironomus nipponensis & 8 & 6 & 3 & 17 & 2.1 \\
\hline Chironomus plumosus & 0 & 0 & 2 & 2 & 0.3 \\
\hline Chironomus yoshimatsui & 0 & 0 & 1 & 1 & 0.1 \\
\hline Chironomus sp. 1 & 0 & 0 & 1 & 1 & 0.1 \\
\hline Cladopelma viridura & 1 & 8 & 0 & 9 & 1.1 \\
\hline **Demicryptochironomus chuncheonensis $\mathrm{n} . \mathrm{sp}$. & 2 & 2 & 0 & 4 & 0.5 \\
\hline Dicrotendipes nervosus & 1 & 0 & 0 & 1 & 0.1 \\
\hline Dicrotendipes septemaculatus & 1 & 6 & 0 & 7 & 0.9 \\
\hline Glyptotendipes tokunagai & 1 & 0 & 0 & 1 & 0.1 \\
\hline Microchironomus tener & 5 & 0 & 0 & 5 & 0.6 \\
\hline Parachironomus arcuatus & 0 & 0 & 1 & 1 & 0.1 \\
\hline *Paracladolema camptolabis & 0 & 0 & 51 & 51 & 6.4 \\
\hline Paratrichocladius rufiventris & 1 & 0 & 0 & 1 & 0.1 \\
\hline Pentapedilum pseudotritum & 0 & 1 & 0 & 1 & 0.1 \\
\hline Polypedilum nubifer & 11 & 7 & 0 & 18 & 2.3 \\
\hline Polypedilum scalaenus & 0 & 2 & 0 & 2 & 0.3 \\
\hline Polypedilum ureshinoensis & 0 & 2 & 0 & 2 & 0.3 \\
\hline Polypedilum yongsanensis & 2 & 29 & 13 & 44 & 5.5 \\
\hline Polypedilum sp. 1 & 0 & 1 & 0 & 1 & 0.1 \\
\hline Stictochironomus A, sp. nov.**** & 0 & 0 & 6 & 6 & 0.8 \\
\hline \multirow{2}{*}{\multicolumn{6}{|c|}{ TANYTARSINI: }} \\
\hline & & & & & \\
\hline **Paratanytarsus haisooni n. sp. & 14 & 3 & 3 & 20 & 2.5 \\
\hline **Tanytar ahyoni n. sp. & 0 & 0 & 34 & 34 & 4.3 \\
\hline *Tanytarsus akantertius & 5 & 55 & 0 & 60 & 7.6 \\
\hline **Tanytarsus kiseogi n. sp. & 1 & 4 & 0 & 5 & 0.6 \\
\hline **Tanytarsus seohyoni $\mathrm{n} . \mathrm{sp}$. & 1 & 3 & 191 & 195 & 24.6 \\
\hline *Tanytarsus takahashii & 0 & 2 & 2 & 4 & 0.5 \\
\hline Tanytarsus tamaoctavus & 0 & 0 & 2 & 2 & 0.3 \\
\hline **Tanytarsus yoni n. sp. & 0 & 0 & 30 & 30 & 3.8 \\
\hline Tanytarsus sp. 1 & 0 & 0 & 4 & 4 & 0.5 \\
\hline \multicolumn{6}{|l|}{ ORTHOCLADIINAE } \\
\hline Cricotopus bicinctus & 1 & 3 & 2 & 6 & 0.8 \\
\hline Cricotopus bimaculatus & 0 & 7 & 7 & 14 & 1.8 \\
\hline Cricotopus parametatibiatus & 0 & 1 & 0 & 1 & 0.1 \\
\hline Cricotopus triannulatus & 0 & 2 & 0 & 2 & 0.3 \\
\hline *Cricotopus tricinctus & 0 & 0 & 1 & 1 & 0.1 \\
\hline Cricotopus sp. 1 & 1 & 0 & 0 & 1 & 0.1 \\
\hline Harnischia japonica & 0 & 2 & 0 & 2 & 0.3 \\
\hline **Orthocladius seonwui n. sp. & 0 & 6 & 0 & 6 & 0.8 \\
\hline Orthocladius suspensus & 0 & 0 & 13 & 13 & 1.6 \\
\hline *Orthocladius yugashimaensis & 0 & 0 & 4 & 4 & 0.5 \\
\hline Orthocladius sp. 1 & 0 & 0 & 3 & 3 & 0.4 \\
\hline *Parakiefferiella bathophila & 0 & 24 & 17 & 41 & 5.2 \\
\hline **Psectrocladius kangi $\mathrm{n} . \mathrm{sp}$. & 2 & 1 & 0 & 3 & 0.4 \\
\hline \multicolumn{6}{|l|}{ TANYPODINAE } \\
\hline Ablabesmyia monilis & 1 & 14 & 31 & 46 & 5.8 \\
\hline Ablabesmyia sp. 1 & 2 & 0 & 9 & 11 & 1.4 \\
\hline Ablabesmyia sp. 2 & 0 & 0 & 7 & 7 & 0.9 \\
\hline Procladius choreus & 2 & 5 & 0 & 7 & 0.9 \\
\hline Procladius sp. 1 & 0 & 2 & 0 & 2 & 0.3 \\
\hline Tanypus punctipennis & 1 & 6 & 0 & 7 & 0.9 \\
\hline \multicolumn{6}{|l|}{ PRODIAMESINAE } \\
\hline *Monodiamesa bathyphila & 0 & 0 & 10 & 10 & 1.3 \\
\hline Total & 72 & 213 & 509 & 794 & 100 \\
\hline
\end{tabular}

*Unrecorded species, $* *$ New species, $* * * \mathrm{Na}(2004)$ reported this species as a new species. 
(6.4\%), Ablabesmyia monilis (Linnaeus) (5.8\%), Polypedilum yongsanensis Ree and Kim (5.5\%), and Tanytarsus ahyoni n. sp. $(4.3 \%)$.

\section{SYSTEMATIC ACCOUNTS}

\author{
Subfamily Chironominae Macquart \\ 1*Genus Demicryptochironomus Lenz \\ 2*Demicryptochironomus chuncheonensis sp. nov.
} (Fig. 1)

Material examined. Holotype: $1 \sigma^{\top 7}$ (CH-4784), Sinsau-dong, Chuncheon-si, Gangwon-do; 1 Aug. 2008; K.Y. Jeong. Paratype: 3 ठ ठ 5378, 5383 collected on 14 Sept. 2008).

Diagnosis. Small to medium, yellowish midge. Wing length $1.7 \mathrm{~mm}$. Superior volsella rather small, finger-like, with a seta at tip. Inferior volsella absent. AR 1.96. LR 1.8.

Description (Male). HEAD: Eye bare, produced dorsomedially. Frontal tubercle (Fig. 1C) moderately large. Antenna dark brown, with 11 segments, AR 1.96. 1-2 postoculars each side; 8-9 verticals. Clypeus brownish yellow, with 11-13 setae. Palp dark brown, with 5 segments: 36, 34, 100, 137, $207 \mu \mathrm{m}$ $(1: 1.0: 28: 3.9: 5.8)$. THORAX: Light yellow in ground color. Antepronotum yellowish, notched, lobes just divided medially. Scutum with brownish yellow vittae (not clearly distinguished); tubercle absent; 5 acrosticals; 7-9 dorsocentrals and 3 prealars each side. Scutellum pale yellow, with 5-6 setae. Postnotum brownish yellow. WING (Fig. 1A): Wing length $1.7 \mathrm{~mm}$. Membrane bare; only $\mathrm{R}$ and $\mathrm{R}_{1}$ with setae. Costa not produced. $\mathrm{R}_{2+3}$ running near $\mathrm{R}_{1}$ and ended near end of $\mathrm{R}_{1}$. RM not pigmented. $\mathrm{FCu}$ distal to $\mathrm{RM}$. $\mathrm{Cu}_{1}$ almost straight. An ending beyond FCu. Anal lobe moderately developed. Squama fringed. LEGS: All Femurs pale. Tibia of fore leg pale dark brown; tibiae of mid and hind legs pale. Tarsi of fore leg pale, slightly darker; tarsi of mid and hind legs pale, gradually darker apically. Apex of fore tibia with rounded scale. Mid and hind tibiae with scaresely separated combs, each with spur. Pulvillus well developed. LR 1.8. ABDOMEN: Pale yellow. HYPOPYGIUM (Fig. 1B): Anal point pale, somewhat broadened, smoothly rounded at tip. Superior volsella rather small, finger-like, with a seta at tip. Inferior volsella absent. Gonostylus fused with gonocoxite, long, relatively slender, pararelle-sided, with medial constriction.

Remarks. The genus Demicryptochironomus is reported for the first time in of Korea. Cranston et al. (1989) reported two subgenera, Demicryptochironomus and Irmakia, and the present new species belongs to subgenus Irmakia, as superior volsella is finger-like and gonostylus is constricted medially. Three species in Japan and one species in England wee reported (Pinder, 1978; Sasa, 1995), all of which have a long, narrow anal point, whereas De. chuncheonensis n.sp. has a rather short, broad anal point.

Genus Paracladopelma Harnisch

${ }^{3 *}$ Paracladopelma camptolabis (Kieffer, 1913) (Fig. 2)

Tendipes camptolabis Kieffer 1913, p. 40.

Paracladopelma camptolabis: Edwards, 1929, p. 387; Pinder, 1978, p. 132; Sasa, 1984, p. 46; Sasa, 1985, p. 37; Sasa, 1988, p. 14; Sasa, 1991, p. 48; Sasa and Okazawa, 1992, p. 41.

Material examined. 11 ه ه (CH-5757, 5765, 5777, 5785, 5789, 5806, 5807, 5832, 5928, 5936, 5970); Sinsau-dong, Chuncheon-si, Gangwon-do; 1 May 2009; K.Y. Jeong.

Diagnosis. Medium sized, light brown species. Wing length $2.2 \mathrm{~mm}$. Superior volsella broad, pad-like, apically expanded, covered with microtrichiae dorsally and many setae along apical margin. Inferior volsella broadly rounded. Gonostylus long, slightly expanded distally. AR 2.2. LR 1.8.

Description (Male). HEAD: Light brown. Eye black, bare, dorsomedially produced. Frontal tubercle (Fig. 2B) rather small. Antenna brown, with 11 flagellomeres; AR 2.24. 1114 postoculars each side. Palp dark brown, with 4 segments: 46, 134, 157, $214 \mu \mathrm{m}(1: 2.9: 3.4: 4.6)$. Clypeus brown, with 15-17 setae. THORAX (Fig. 2E): yellowish brown in ground color. Antepronotum dark brown, narrowed anteriorly, weakly notched dorsomedially, with 7-8 minute setae on ventral side. Scutum yellowish brown, with dark brown vittae; 12 acrosticals, 7-8 dorsocentrals and 3 prealars each side. Scutellum yellowish brown with 5-7 setae. Postnotum dark brown. WING (Fig. 2A): Membrane bare. Only distal half of $\mathrm{R}_{4+5}$ and basal $\mathrm{R}$ setosed. Costa not extended. $\mathrm{R}_{2+3}$ ending near end of $\mathrm{R}_{1}$. FCu distal to RM. $\mathrm{Cu}$ almost straight. Anal lobe poorly developed. Squama with 2-3 setae. Brachiolum with 2-3 setae. WL $2.2 \mathrm{~mm}$. LEGS: Uniformly brown. Apex of fore tibia with small, rounded projection; combs of mid and hind tibiae fused, both bearing a spur. Pulvillus developed. LR 1.8. ABDOMEN: Uniformly pale dark brown. HYPOPYGIUM (Fig. 2C): Anal tergite produced apically, with numerous setae both side of anal point. Anal point long, narrow, parallel-sided. Superior volsella broad, pad-like, strongly expanded distally, with inner round and outer angulated apical corners; covered with microtrichiae dorsally and many setae along apical margin. Inferior volsella (Fig. 2D) broadly rounded posteriorly, covered with microtrichiae. Gonostylus long, slightly expanded from apical one-third, smoothly tapered

\footnotetext{
$1 *$ 반음깔따구속(신칭), ${ }^{2 *}$ 춘천반음깔따구(신칭), ${ }^{3 *}$ 오리발육촌깔따구(신칭)
} 


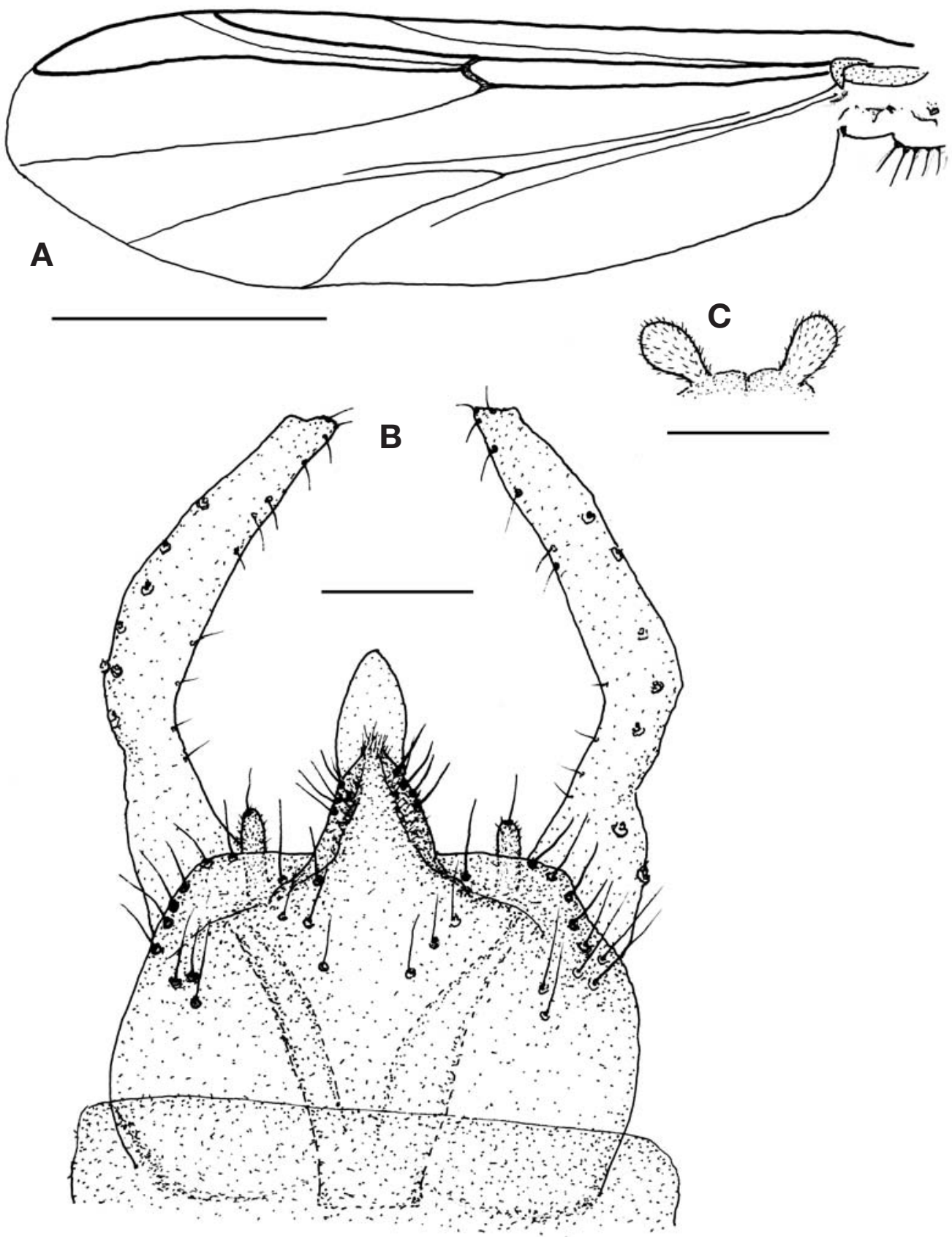

Fig. 1. Demicriptochironomus chuncheonensis n. sp. (Male). A, Wing; B, Hypopygium; C, Frontal tubercle. Scale bars=0.5 mm (A), $0.05 \mathrm{~mm}(B, C)$.

apically.

Remarks. The anal point of the present species is almost parallel-sided, whereas Pinder (1978) and Sasa (1984) described that anal point of Paracladopelma camptolabis was slightly expanded distally. Otherwise most characters of the present species are well coincided with those of camptolabis.
Genus Stictochironomus Kieffer

${ }^{1 *}$ Stictochironomus sinsauensis sp. nov. (Fig. 3) Material examined. Holotype: 가 (CH-6063), Sinsau-dong, Chuncheon-si, Gangwon-do; 1 May 2009; K.Y. Jeong. Para-

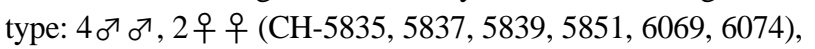
data same as holotype.

\footnotetext{
1*신사우반지깔따구(신칭)
} 

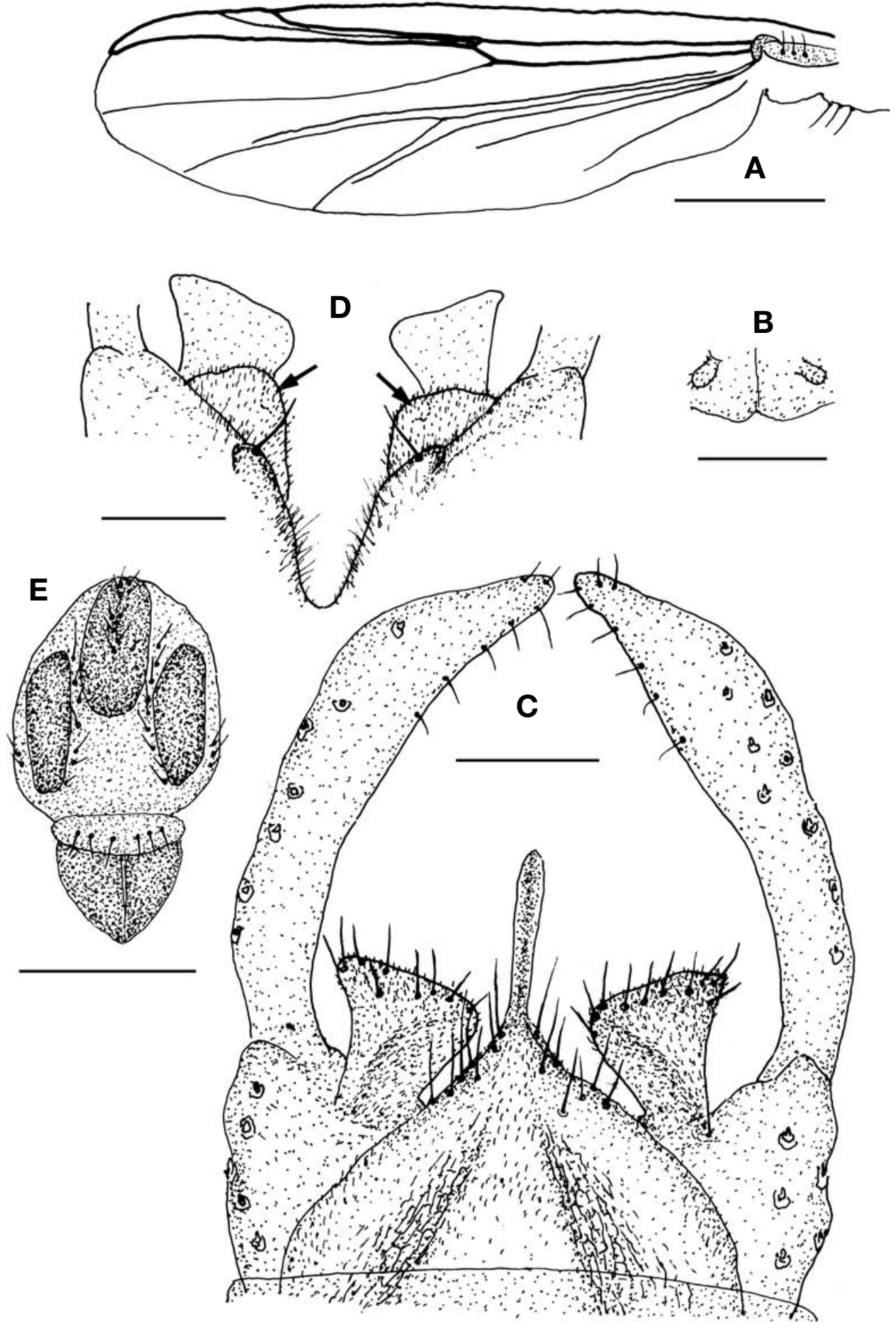

Fig. 2. Paracladopelma camptolabis (Male). A, Wing; B, Frontal tubercle; C, Hypopygium; D, Inferior volsella (ventral view of hypopygium); $E$, Scutum, sculellum and postnotum (dorsal view). Sacle bars $=0.5 \mathrm{~mm}(A, E) ; 0.05 \mathrm{~mm}(B, D)$. 


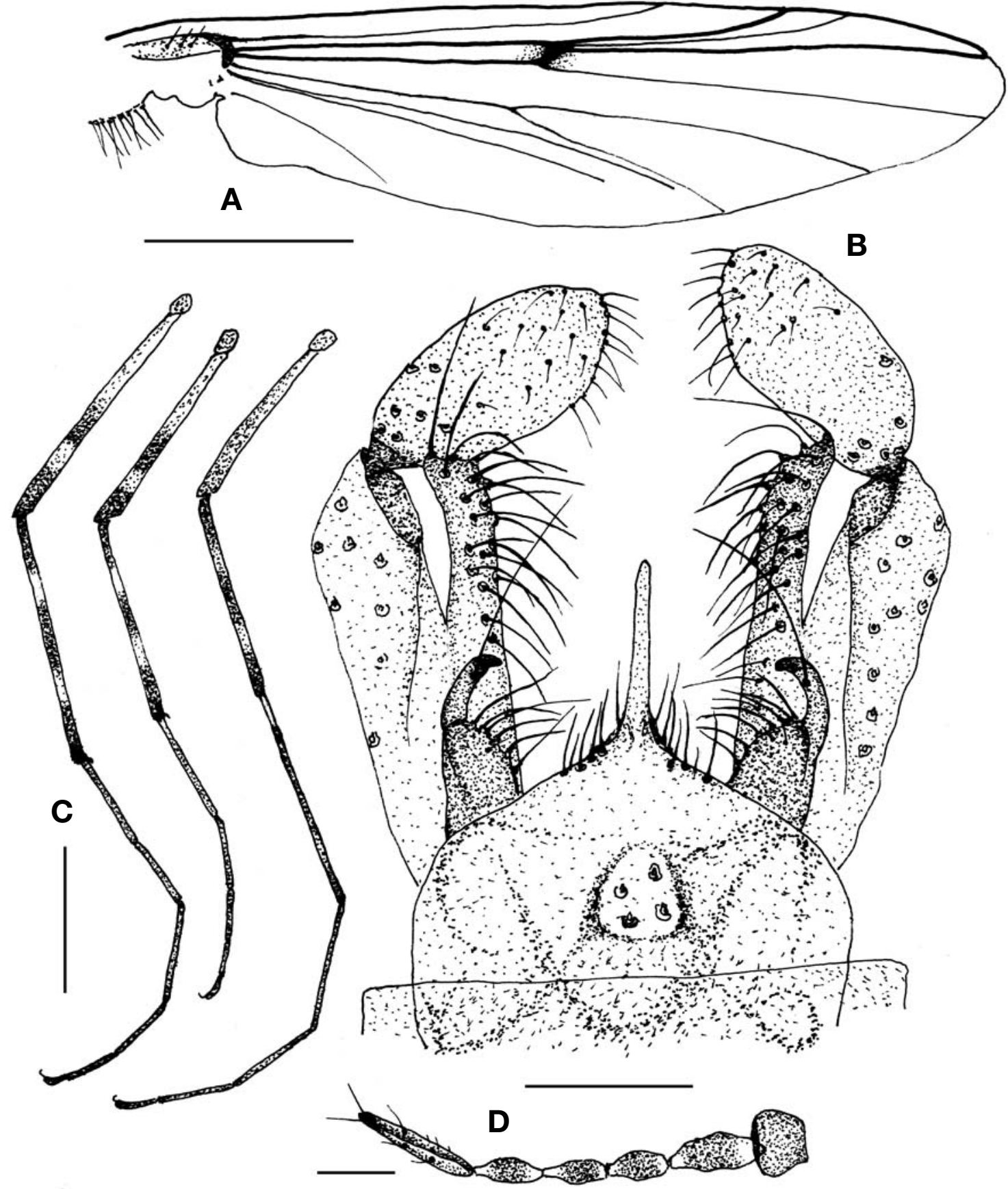

Fig. 3. Stictochironomus sinsauensis $n$. sp. (Male). A, Wing; $B$, hypopygium; $C$, Fore, mid and hind legs, from right; $D$, Antenna of female. Scale bars $=1.0 \mathrm{~mm}(A, C), 0.1 \mathrm{~mm}(B, D)$.

Diagnosis. Medium to large, dark brown species. Wing length $3.9 \mathrm{~mm}$. Superior volsella abruptly curved at tip, with a long subapical seta and 6-7 basal setae. Inferior volsella very long, as long as gonocoxite. Gonostylus very wide $(80 \mu \mathrm{m}$ wide, $160 \mu \mathrm{m}$ long). AR 2.3. LR 1.13.

Description (Male). HEAD: Brown. Eye black, bare, with dorsomedial projection. Frontal tubercle absent. Antenna dark brown, with 13 segments; AR 2.3. Palp dark brown, with 5 segments: $43,96,179,189,250 \mu \mathrm{m}(1: 2.3: 4.2: 4.4$ : 5.8). Clypeus dark brown, with 35 setae. THORAX: Dark brown in ground color. Antepronotum dark brown, dorsally apart, flat and pressed to scutum, without setae. Scutum uni- 

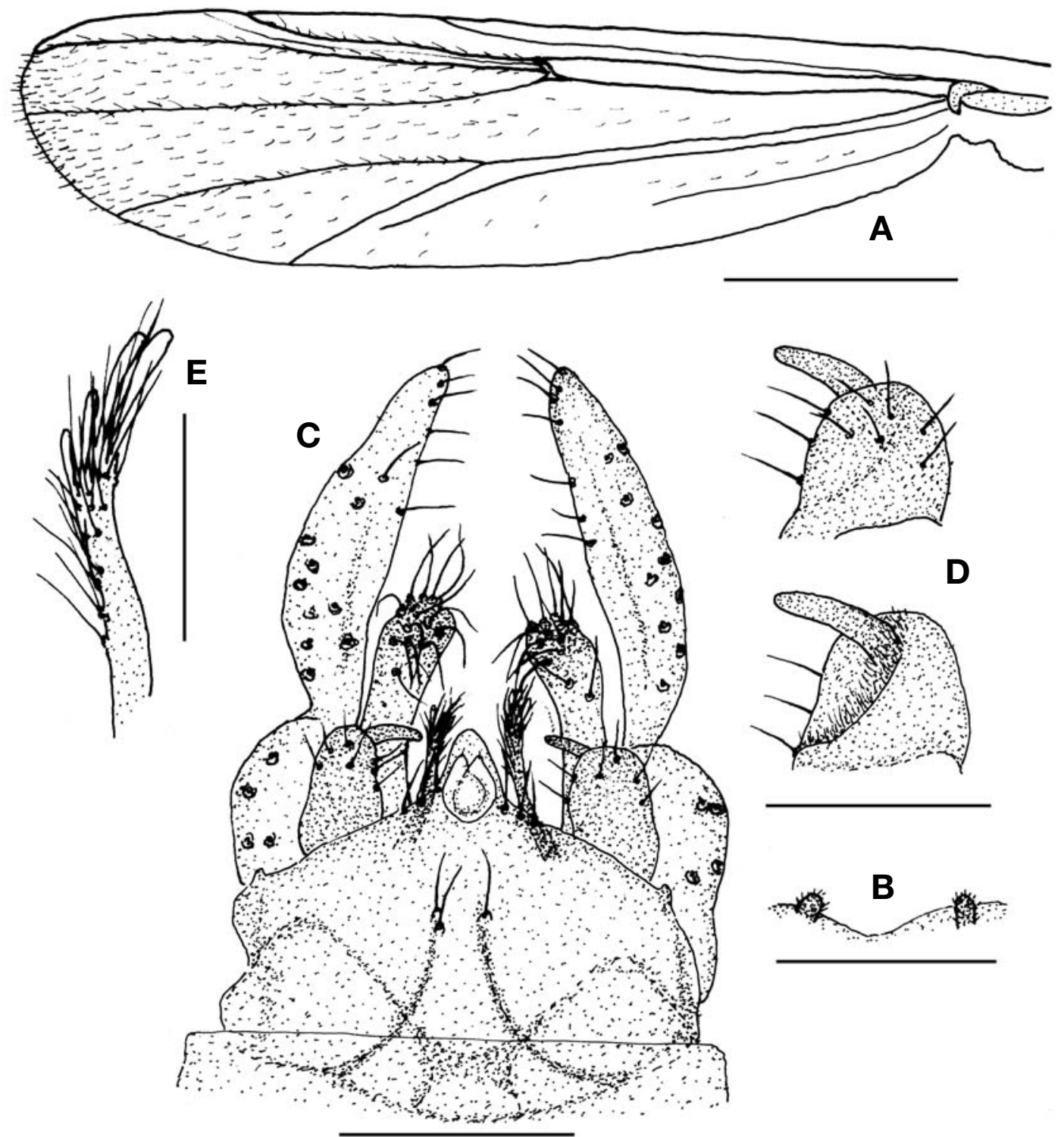

Fig. 4. Paratanytarsus haisooni n. sp. (Male). A, Wing; $B$, Frontal tubercle; $C$, Hypopygium; $D$, Superior volsella (above dorsal, bellow ventral); $E$, Median volsella. Scale bars $=0.5 \mathrm{~mm}(A), 0.05 \mathrm{~mm}(B, D, E), 0.1 \mathrm{~mm}(C)$.

formly dark brown, vittae absent; tubercle present; 8 acrosticals, 10-11 dorsocentrals each side. Scutellum dark brown, with 38-40 setae. Postnotum dark brown. WING (Fig. 3A): Wing length $3.9 \mathrm{~mm}$. Membrane bare, dark spot around RM. Vein $\mathrm{R}$, distal $1 / 4$ of $\mathrm{R}_{4+5}$ and apical end of $\mathrm{R}_{1}$ setosed. Costa not produced. $R_{2+3}$ running middle of $R_{1}$ and $R_{4+5}$, ending distal $1 / 3$ between end of $R_{1}$ and $R_{4+5}$. RM slightly distal to $\mathrm{FCu} . \mathrm{Cu}_{1}$ almost straight. Anal lobe moderately developed. Squama fringed. Archlus dark brown; brachiolum dark brown, with 3 setae. LEGS (Fig. 3C): femur dark brown, with obscure pale ring subapically (particularly fore femur's subapical band not discernible). Fore tibia dark brown with subapical pale ring (not clearly defined); mid and hind tibiae dark brown with two pale ring on basal $1 / 3$ and distal $2 / 5$. All tarsi dark brown. Two combs of mid and hind tibiae comfused, each with a short seta. Pulvillus short. LR 1.13. ABDOMEN: Tergites dark brown (darker in middle), with yellowish brown along apical margin. HYPOPYGIUM (Fig. 3B): Anal tergite with several setae on both basal sites of anal point. Anal point long, slender, paralled-sided. Superior volsella slightly curved inward and abruptly curved at tip, with a subapical long seta and 6-7 setae basally. Inferior volsella very long (as long as gonocoxite) with numerous setae. Gonocoxite long, rather slender. Gonostylus extremely wide, somewhat rectingular 
(80 $\mu \mathrm{m}$ wide $\times 160 \mu \mathrm{m}$ long), with smoothly rounded at tip. Female. Generally same as male, except usual sexual differences. Antenna (Fig. 3D) 5 segmented: segments I-IV dark brown with basal and distal pale rings, segment $\mathrm{V}$ dark brown with 2 subapical setae.

Remarks. This new species is similar to Stictochironomus sticticus (Fabricius), with the following differences: (1) gonostylus of the former much larger and wider $(2 \times$ longer than wide), whereas that of the later narrower $(3.3 \times$ longer than wide), (2) inferior volsella slightly longer or as long as gonocoxite in the former, whereas shorter than gonocoxite in the later, and (3) abdominal tergites dark brown, with yellowish brown apical margin in the former, whereas dark brown, with hind margin more silvery white (Edwards, 1929; Pinder, 1978). Stictochironomus sinsauensis n. sp. is also similar to Stictochironomus A, sp. nov. (Na, 2004) in general morphology, but the former species has no dark spots on wing membrane, and somewhat rectangular-formed gonostylus, while the later species has 6 dark markings on wing membrane and oval-formed gonostylus.

Genus Paratanytarsus Thienemann and Bause

1 *Paratanytarsus haisooni sp. nov. (Fig. 4)

Material examined. Holotype: $1 \sigma^{\top}$ (CH-4794), Sinsau-dong, Chuncheon-si, Gangwon-do; 1 Aug. 2008; K.Y. Jeong. Paratype: 8 ठ ठ 4811, 4813), same data as holotype.

Diagnosis. Yellowish brown, medium sized midge. Wing length $2.0 \mathrm{~mm}$. Anal point short, broad, rounded at tip, with conspicuous anal crests. Superior volsella round, with 7 setae dorsally; digitus moderately long. Median volsella moderately long, with both spoon shaped and simple setae. AR 1.2. LR 1.5.

Description (Male). HEAD: Yellowish brown. Eye black; moderately produced dorsomedially. Frontal tubercle present (Fig. 4B). Antenna yellowish brown, with 13 segments; AR 1.2. Clypeus brown, with 10 setae. Palp pale dark brown, with 5 segments: 29, 50, 130, 116, $202 \mu \mathrm{m}(1: 1.8: 4.6: 4.1$ : 7.1). THORAX: Yellowish brown in ground color. Antepronotum brown, lobes separated. Scutum dark brown; vittae not clear; 11 elected acrosticals; 6 strong dorsocentrals each side, with clear puctuation. Scutellum dark brown, with 6 setae. Postnotum dark brown. preepisternum brown. WING (Fig. 4A): Wing length $2.0 \mathrm{~mm}$. Wing membrane with macrotrichiae, mostly on distal half. Costa not produced. $\mathrm{R}_{4+5}$ distal to $\mathrm{M}_{3+4}$. $\mathrm{R}_{2+3}$ not clear. $\mathrm{Cu}_{1}$ straight. Anal lobe weakly developed. Squama bare. LEGS: Uniformly pale brown. Apex of fore tibia with a short spur; Mid and hind tibiae with separat- ed combs, each with a spur. Pulvillus absent. LR 1.5. ABDOMEN: Brownish pale yellow. HYPOPYGIUM (Fig. 4C): Anal tergite moderately produced, with 2-4 setae on base of anal crests. Anal point short, broad, rounded at tip, with conspicuous anal crests. Superior volsella (Fig. 4D) round, with 7 short setae dorsally; digitus well developed, moderately long, with rounded tip, microtrichiae on outerlateral side and on base of digitus ventrally. Median volsella (Fig. 4E) moderately long with both narrow spoon-shaped and simple setae. Inferior volsella sylindrical, slightly expanded apically with 13-17 recurbed setae. Gonostylus slender, smoothly tapered distally, with 10-16 moderately long setae inner-laterally.

Remarks. This new species resemples in general morphology to Paratanytarsus miikesecundus (Sasa, 1985) collected at Lake Miike, Japan. However, it can be clearly separated using the following characteristics: (1) the wing membrane covered with macrotrichiae mostly on distal half in the former, whereas the membrane thickly covered with macrotrichiae including basal portion, (2) the median volsella moderately long, with only a few spoon shaped setae in the former, whereas it much longer, extending beyond tip of inferior volsella, with many spoon shaped setae in the later, (3) LR of the former is 1.5 , whereas that of the later is 1.9 , and (4) anal tergite of the former without a dorsal lobe nor tubercles, whereas that of the later with a conically shaped dorsal lobe and a pair of small conical tubercles (Sasa, 1985).

\section{Genus Tanytarsus v.d. Walp \\ ${ }^{2 *}$ Tanytarsus ahyoni sp. nov. (Fig. 5)}

Material examined. Holotype: 1 ऽ (CH-5783), Sinsau-dong, Chuncheon-si, Gangwon-do; 1 May 2009; K.Y. Jeong. Paratype: 10 ఠ 『 (CH-5800, 5809, 5874, 5900, 5935, 5954, 6012, $6027,6159,6163), 5$ 우 우 (CH-5787, 5790, 5908, 6031, 6156), same as holotype.

Diagnosis. Small to medium size, brownish yellow midge. Wing length $2.4 \mathrm{~mm}$. Anal point slender, tapered apically, with pointed tip, with 1-3 spines between distinct crests. Superior volsella more or less oval, with apical projection; digitus rather long, clavate form. Median volsella short, directed internally, with numerous simple setae. AR 1.2. LR 2.0. Description (Male). HEAD: Brownish yellow. Eye black, bare, slightly produced dorsomedially. 8-11 postoculars. Antenna dark brown, with 13 flagellomeres; AR 1.2. Palp pale dark brown, with 4 segments: $39,132,143,239 \mu \mathrm{m}$ (1 : $3.4: 3.7: 6.1$ ). Clypeus brownish yellow, with 11 setae. Frontal tubercle (Fig. 5B) large, slightly tapered distally. THORAX: Brownish yellow in ground color. Antepronotum yellowish

\footnotetext{
$1 *$ 해순옆장부깔따구(신칭), ${ }^{2 *}$ 아현장부깔따구(신칭)
} 


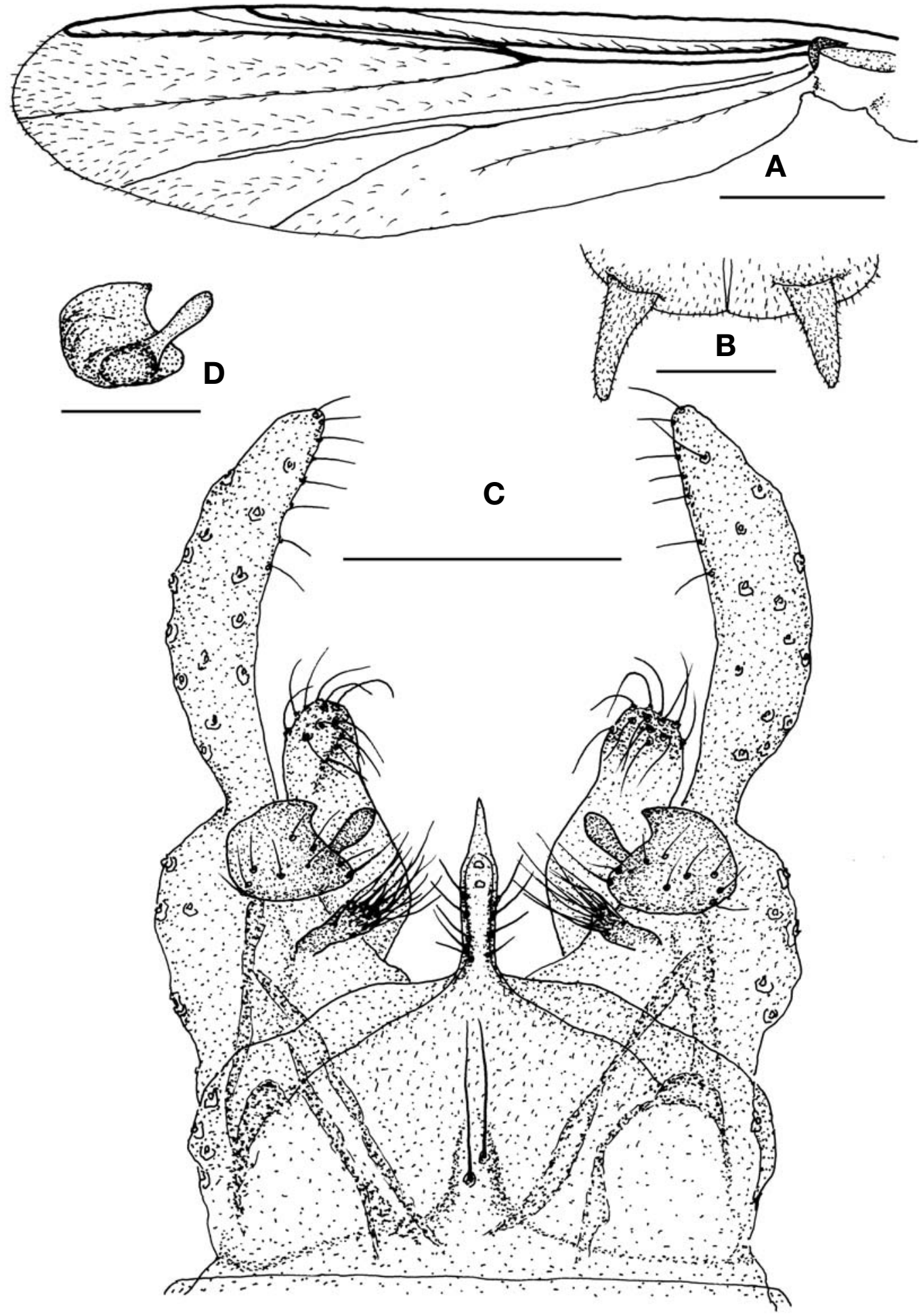

Fig. 5. Tanytarsus ahyoni $\mathrm{n}$. sp. (Male). A, Wing; $B$, Frontal tubercle; $C$, Hypopygium; $D$, Superior volsella (ventral). Scale bars=0.5 mm (A), $0.1 \mathrm{~mm}(\mathrm{C}), 0.05 \mathrm{~mm}(\mathrm{~B}, \mathrm{D})$.

brown dorsally, yellow ventrally, without setae. Scutum brownish yellow, with dark brown vittae, overreaching antepronotum; tubercle absent; 7-8 pale, long acrosticals, 58 dorsocentrals each side, both arising from distinct pale pits; 

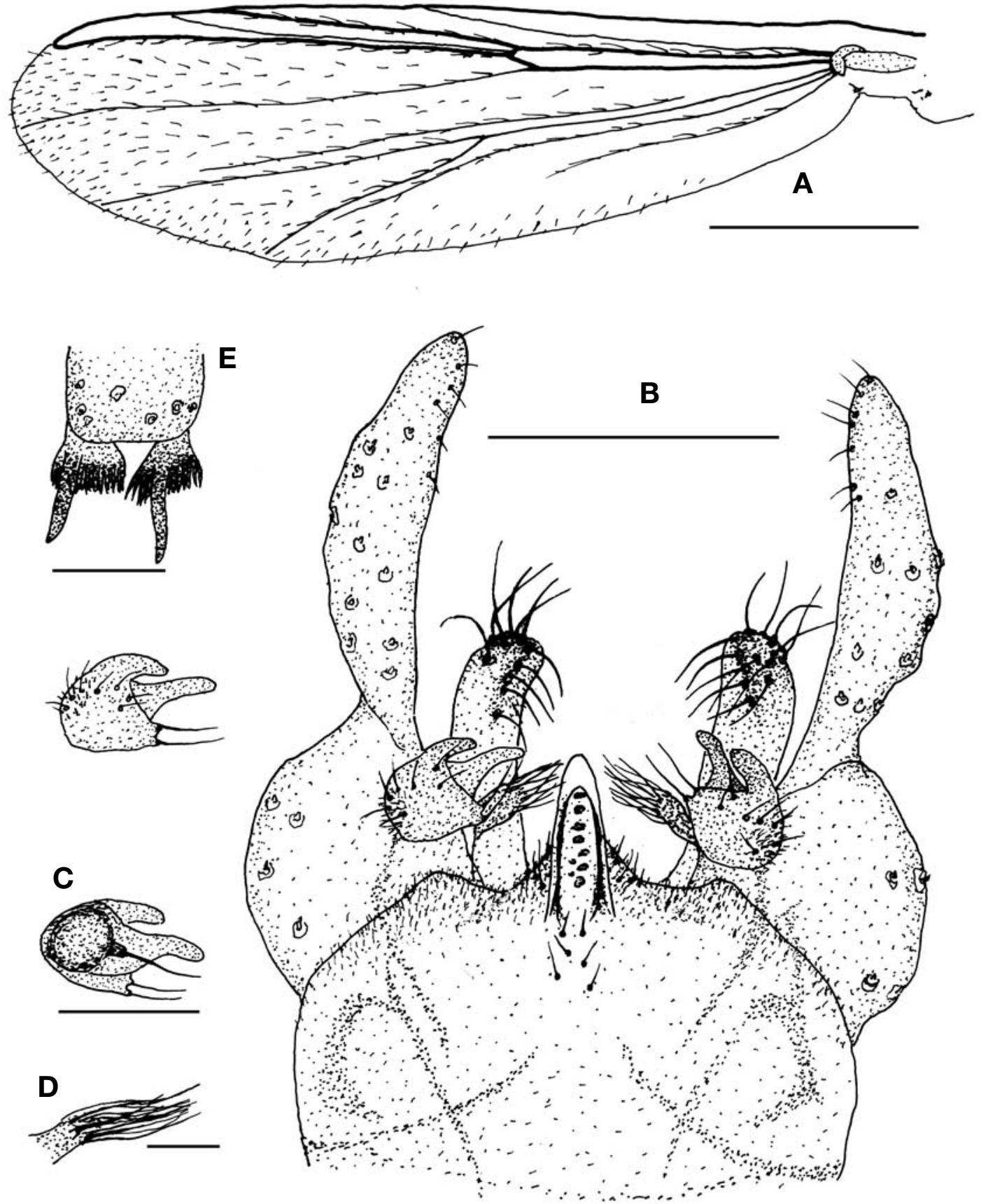

Fig. 6. Tanytarsus akantertius Sasa and Kamimura, 1987 (Male). A, Wig; B, Hypopygium; C, Dorsal (above) and ventral (below) superior volsella; D, Median volsella; E, Comb scales of mid tibia, Scale bars=0.5 mm (A), $0.1 \mathrm{~mm}(B), 0.05 \mathrm{~mm}(C, E), 0.02 \mathrm{~mm}(\mathrm{D})$.

1-2 prealars. Scutellum brownish yellow with 4-5 setae. Postnotum dark brown. WING (Fig. 5A): Wing length $2.4 \mathrm{~mm}$. Membrane covered with macrotrichiae, denser distally. Costa not produced. $\mathrm{R}_{2+3}$ ending in proximal $1 / 3$ between ends of $\mathrm{R}_{1}$ and $\mathrm{R}_{4+5}$. FCu distal to $\mathrm{RM}$. $\mathrm{R}_{4+5}$ ending slightly distal to apex of $\mathrm{M}_{3+4}$. $\mathrm{Cu}_{1}$ almost straight. Anal lobe not developed. Squama bare. LEGS: Uniformly yellowish brown. Combs of mid and hind tibiae well separated, each with a short spur. Pulvillus absent. LR 2.0. ABDOMEN: All tergites uniformly pale, often with purple pigments on tergite VIVIII. HYPOPYGIUM (Fig. 5C): Tergite IX rather rectiangular, with 1-2 long setae on middle. Anal point slender tapered 
apically, with paired crests and 1-3 pale spines and with 4-5 lateral setae each side. Superior volsella oval with apical projection, with 1 long and 5-8 short setae; digitus rather long, clavate (Fig. 5D). Median volsella short, directed internally, with numerous simple setae. Inferior volsella sylindrical, broad, with 19-23 strong recurved setae. Gonostylus slightly curved inward, with 10-14 inner-lateral setae.

Female. General morphology same as male, except usual sexual differences. Frontal tubercle is rather smaller than male. Antenna yellowish brown, with 4 segments; 123, 79, $79,171 \mu \mathrm{m}$. Wing length $2.1 \mathrm{~mm}$.

Remarks. Tanytarsus ahyoni n. sp. has large horn-shaped frontal tubercles and a sharply pointed anal point, which are not commonly found in any other species of Tanytarsus.

Genus Tanytarsus v.d. Wulp

${ }^{1 *}$ Tanytarus akantertius Sasa and Kamimura, 1987 (Fig. 6)

Tanytarus akanteritius Sasa and Kamimura, 1987, p. 21-22.

Material examined. $4 \sigma^{7}$ o $^{7}$ (CH-4782, 4810, 4815, 4816): Sinsau-dong, Chuncheon-si, Gangwon-do; 1 Aug. 2008, K.Y. Jeong. $20 \sigma^{7} \sigma^{\top}, 3$ 우 우: Locality same as above; 14 Sept. 2008; K.Y. Jeong.

Diagnosis. Pale yellow, small to medium sized midge. Wing length $2.0 \mathrm{~mm}$ in male and $1.8 \mathrm{~mm}$ in female. Superior volsella with prominently produced lobe posteriorly, 2 long inner marginal setae and 1 long ventral setae; digitus long, distinctly produced. Median volsella short with numerous simple setae. AR 1.1. LR 2.4.

Description (Male). HEAD: Pale yellow. Eye black, bare, slightly produced dorsomedially. Frontal tubercle minute. 78 postoculars. Antenna pale dark brown, with 13 segments; AR 1.1. Palp pale yellow, with 4 segments: 43, 122, 137, $216 \mu \mathrm{m}(1: 2.8: 3.2: 5.0)$. Clypeus yellow, with $13-15$ setae. THORAX: Yellow in ground color. Antepronotum poorly developed, lobes widely separated medially. Scutum distinctly overreaching antepronotum, vittae absent; 15-18 acrosticals; 6-8 dorsocentrals each side. Scutellum pale yellow, with 6 setae. Postnotum pale yellow anteriorly, brownish yellow posteriorly. WING (Fig. 6A): Wing length $2.0 \mathrm{~mm}$. Membrane with macrotrichiae, mostly on distal half. Costa not produced. $R_{2+3}$ running close to $R_{4+5}$, and ending in proximal $1 / 3$ between ends of $R_{1}$ and $R_{4+5}$. $R M$ proximal to $F C u$. Most veins setosed. Anal lobe not developed. Squama bare. Brachiolum pale without seta. LEGS: Uniformly pale yellow. Mid and hind tibial combs widely separated, each with a spur (Fig. 6E). Pulvillus absent. LR 2.4. ABDOMEN: Uniformly pale yellow. HYPOPYGIUM (Fig. 6B): Anal tergite produced posteriorly, with several small setae on base of anal point; anal tergite band pale, widely separated. Anal point round apically, with distinct crests and 9-10 spine clusters. Superior volsella (Fig. 6C) roughly trapezoidal with prominently produced lobe posteriorly, with 6-7 short dorsal setae, 2 long inner-marginal setae and a long ventral seta from a cylindrical base; digitus distinctly produced. Median volsella (Fig. 6D) short with many simple setae. Inferior volsella sylindrical, with recurved setae apically. Gonostylus round apically, with slightly curved inner margin.

Female. Same as male, except usual sexual differences. Antenna pale yellow, pale dark brown apically, with 4 segments (1st and 2nd segments fused). Wing length $1.8 \mathrm{~mm}$.

Remarks. The present species is generally well coincided to Tanytarsus akantertius, except some minor differences: (1) the former is larger in body size (WL $2.0 \mathrm{~mm}$ vs $1.4-1.5 \mathrm{~mm}$ ), (2) mid tibia with 2 short spurs in the former, whereas a long spur in the later, and (3) anal point with 7-9 spine clusters whereas 5 spine clusters in the later (Sasa, 1983).

\section{Genus Tanytarsus v.d. Wulp \\ ${ }^{2 *}$ Tanytarsus kiseogi sp. nov. (Fig. 7)}

Material examined. Holotype: $1 \sigma^{7}$ (CH-5377), Sinsau-dong, Chuncheon-si, Gangwon-do; 14 Sept. 2008; K.Y. Jeong. Paratype: $3 \sigma^{7} \sigma^{7}$ (CH-4804, 4807, 4809), Data same as holotype; 1 우 (CH-5971), locality same as holotype, 1 May 2009; K.Y. Jeong.

Diagnosis. Rather small sized, pale yellow midge. Wing length $1.8 \mathrm{~mm}$ in male and $1.7 \mathrm{~mm}$ in female.

Scutal vittae absent. Superior volsella oval, with 7-8 dorsal setae; digitus small, not reaching to margin of superior volsella. Median volsella short, with both lamelated and simple setae. AR 1.2. LR 2.8.

Description (Male). HEAD: Yellow. Eye black, bare, slightly produced dorsomedially. Frontal tubercle rather small (Fig. 7E). 7-8 postoculars. Antenna pale dark brown, with 13 segments, AR 1.2. Clypeus yellow, with 16 setae. Palp pale yellow, with 5 segments: $38,45,121,129,216 \mu \mathrm{m}(1: 1.2: 3.2$ : $3.4: 5.7)$. THORAX: Pale yellow in ground color. Antepronotum pale, reduced, widely separated medially. Scutum pale yellow, vittae absent, tubercle absent, 14 acrosticals, 7-9 dorsocentrals each side. Scutellum pale, wih 5 setae. Postnotum pale yellow. WING (Fig. 7A): Wing length $1.8 \mathrm{~mm}$. Membrane with macrotrichiae, mostly on distal half. All veins setosed, except subcosta and M. Costa not extended. $R_{2+3}$ ending in proximal $1 / 3$ between ends of $R_{1}$ and $R_{4+5}$. $R M$ proximal to $\mathrm{FCu}$. Anal lobe not developed. Squama bare. Brachiolum with 1 seta; archlus dark brown. LEGS: All

\footnotetext{
1*집게장부깔따구(신칭), ${ }^{2 *}$ 기석장부깔따구(신칭)
} 

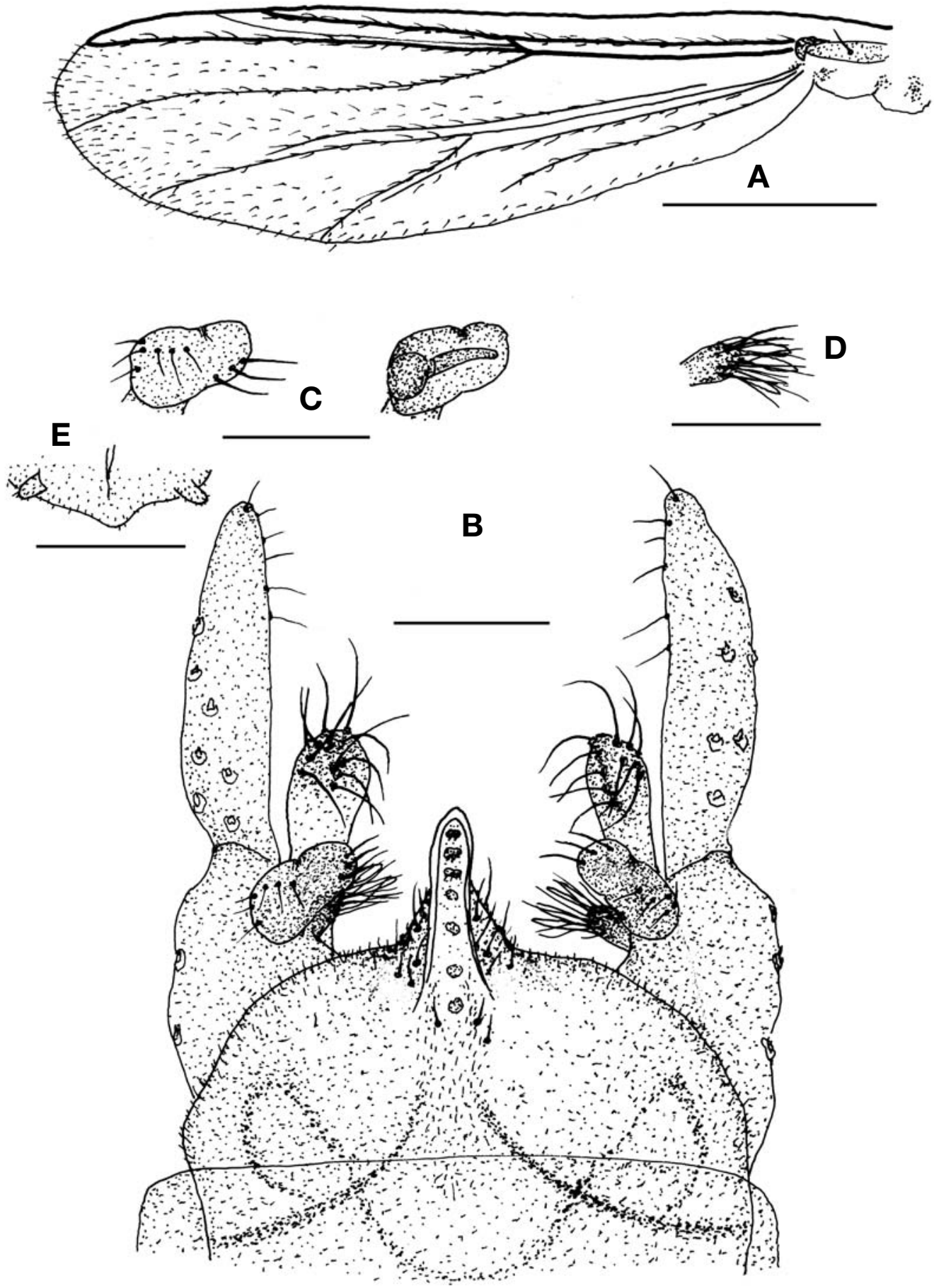

Fig. 7. Tanytarsus kiseogi n. sp. (Male). A, Wing; B, Hypopygium; C, Dorsal (left) and ventral (right) view of superior volsella; $D$, Median volsella; $E$, Frontal tubercle. Scale bars $=0.5 \mathrm{~mm}(A), 0.05 \mathrm{~mm}(B-D), 0.1 \mathrm{~mm}(E)$.

segments pale yellow, only fore torsi slightly darker. Mid and hind tibial combs widely separated, each with a long spur. Pulvillus absent. LR 2.8. ABDOMEN: Uniformly pale yellow. HYPOPYGIUM (Fig. 7B): anal tergite posteriorly produced, with several small setae on each side of anal point.
Anal point parallel-sided, with round apex, with distinct crest and 6-7 spine clusters. Superior volsella (Fig. 7C) roughly oval in shape, with 7-8 setae dorsally; digitus short, not extending to margin of superior volsella. Inferior volsella sylindrical, slightly clubbed distally, with 12-14 setae. Median 
volsella (Fig. 7D) short, with both lamelliform and simple setae. Gonostylus slightly tapered apically, with almost straight inner margin.

Female. Most characters same as in male, except usual sexual differences. Frontal tubercles smaler than that of male. Antenna pale yellow, with 5 segments. Wing length $1.7 \mathrm{~mm}$.

Remarks. The present species is close to Tanytarsus unagiseptimus Sasa in general morphology, with the following differences: (1) postnotum of the former is pale yellow, whereas that of the later is dark brown, (2) vittae of scutum is absent in the former, whereas dark brown vittae present in the later, (3) digitus with round apex in the former, whereas sharply pointed apex in the later, and (4) median volsella with both lamelated and simple setae in the former, whereas median volsella with leaf-like setae only in the later (Sasa, 1985).

Genus Tanytarsus v.d. Wulp

${ }^{1 *}$ Tanytarsus seohyoni sp. nov. (Fig. 8)

Material examined. Holotype: $1 \sigma^{\top}$ (CH-5905), Sinsau-dong, Chuncheon-si, Gangwon-do; 1 May 2009; K.Y. Jeong. Paratype: 10 ठ $^{7}$ (CH-5763, 5767, 5771, 5772, 5773, 5774, $5776,5903,5904,6019), 3$ 우 우 (CH-5770, 5781, 5791), data same as holotype.

Diagnosis. Medium sized, brown species. Wing length 2.1 $\mathrm{mm}$ in male, $2.2 \mathrm{~mm}$ in female. Superior volsella somewhat round, inner margin rather straight, with posteriorly produced lobe twisted upward; digitus long, well extended margin of superior volsella. Median volsella short with many simple setae. AR 1.1. LR 2.2.

Description (Male). HEAD: Light brown. Eye black, bare, slightly produced dorsomedially. 7-8 postoculars. Antenna dark brown, with 13 segments, AR 1.1. Frontal tubercle (Fig. 8B) small, widely separated each other. Clypeus light brown, with 13 setae. Palp pale dark brown, with 5 segments: 36, 48, 98, 132, $203 \mu \mathrm{m}(1: 1.3: 2.7: 3.6: 5.6)$. THORAX: Light brown in ground color. Antepronotum dark brown, tapered dorsally, widely separated medially. Scutum overreaching antepronotum, with dark brown vittae; 11 acrosticals, 8-9 dorsocentrals and 1-2 prealars each side. Scutellum light brown, with 3-4 setae. Postnotum brown. Halter pale. WING (Fig. 8A): Wing length $2.1 \mathrm{~mm}$. Membrane with macrotrichiae, mostly on distal half. Costa not extended. $\mathrm{R}_{2+3}$ ending in proximal $1 / 3$ between apices of $R_{1}$ and $R_{4+5}$. End of $R_{4+5}$ distal to end of $\mathrm{M}_{3+4}$. $\mathrm{RM}$ proximal to $\mathrm{FCu}$. An over reaching $\mathrm{FCu}$. Anal lobe not developed. Squama bare. LEGS: Uniformly brown. Mid and hind tibial combs widely separated, each with a spur. Pulvillus absent. LR 2.2. ABDOMEN: Uniformly pale brown. HYPOPYGIUM (Fig. 8C): Anal tergite pro- duced posteriorly, with several minute setae on base of anal point. Anal tergite band separate. Anal point slightly tapered, tip rounded, with distinct crest and 7-8 spine clusters. Superior volsella (Fig. 8D) dark brown, somewhat round, straight inner margin, with posteriorly produced lobe twisted upward, with 2-3 inner-lateral setae, a long ventral seta from a cylindrical base, and 7-8 short dorsal setae; digitus rather long, well produced from margin of superior volsella. Median volsella (Fig. 8E) short, directed internally, with simple setae. Inferior volsella sylindrical with 11-15 setae distally. Gonostylus long, narrowed at base, with almost straight innermargin and round apex.

Female. Same as male, except usual sexual differences. Antenna pale dark brown, with 4 segments (1st and 2nd segments fused). Wing length $2.2 \mathrm{~mm}$.

Remarks. Morphological characters of the present species are very similar to those of Tanytarsus akantertius Sasa and Kamimura. However, this new species has brown body color, 8-9 acrosticals, dark brown vittae and 2 scutellares, whereas Ta. akantertius has uniformly pale yellow body color, 13-15 acrosticals, no vittae and 4 scutellares (Sasa and Kamimura, 1987).

Genus Tanytarsus v.d. Wulp

${ }^{2 *}$ Tanytarsus takahashii Kawai and Sasa, 1985 (Fig. 9)

Tanytarsus takahashii Kawai and Sasa, 1985, p. 22; Sasa and Kawai 1987, p. 38; Sasa, 1989, p. 65; Sasa, 1990, p. 36; Sasa, 1993, p. 78.

Material examined. 2 જ Chuncheon-si, Gangwon-do; 14 Sept. 2008; K.Y. Jeong; $2 \sigma^{7}$ (С (CH-5957, 5977): Locality same; 1 May 2009; K.Y. Jeong.

Diagnosis. Brownish yellow, small to medium species. Wing length $2.2 \mathrm{~mm}$. Superior volsella somewhat elongated round form, slightly constricted at distal 1/3; digitus distinct, separately oriented from superior volsella. Median volsella extraordinarily long, slightly curved outward, with long simple setae. AR 1.1. LR 2.63.

Description (Male). HEAD: Brownish yellow. Frontal tubercle moderately large (Fig. 9B). 6-7 postoculars each side. Antenna dark brown, with 13 segments, AR 1.1. Clypeus brownish yellow, with 11 setae. Palp pale brown, with 4 segments: $36,121,129,211 \mu \mathrm{m}(1: 3.4: 3.6: 5.9)$. THORAX: Brownish yellow in ground color. Antepronotum pale yellow, bare, poorly developed, widely separated medially. Scutum overreaching antepronotum, yellowish brown vittae indistinct; 7 dorsocentrals each side. Scutellum pale yellow, with 1-2 setae. Postnotum yellowish brown. Hater pale. WING (Fig.

\footnotetext{
$1 *$ 서현장부깔따구, ${ }^{2 *}$ 다까하시장부깔따구(신칭)
} 


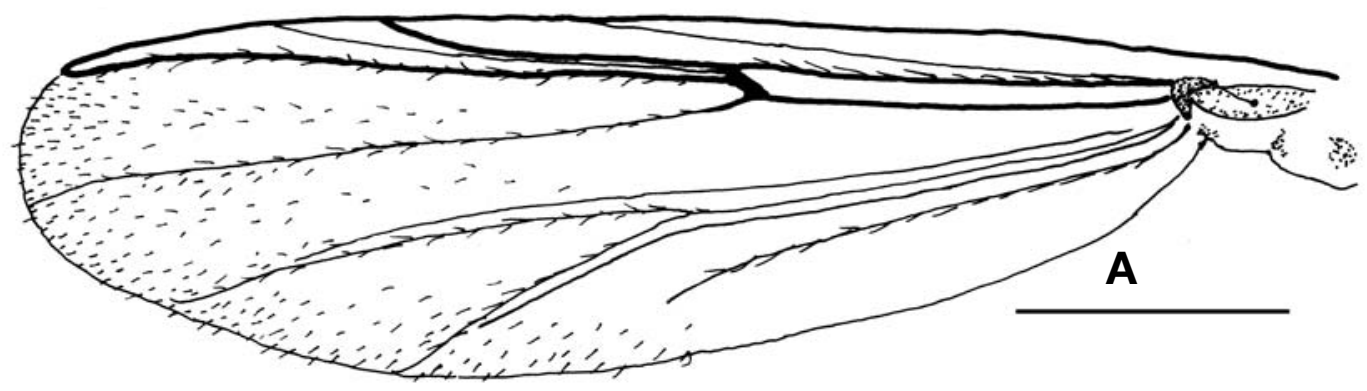

B

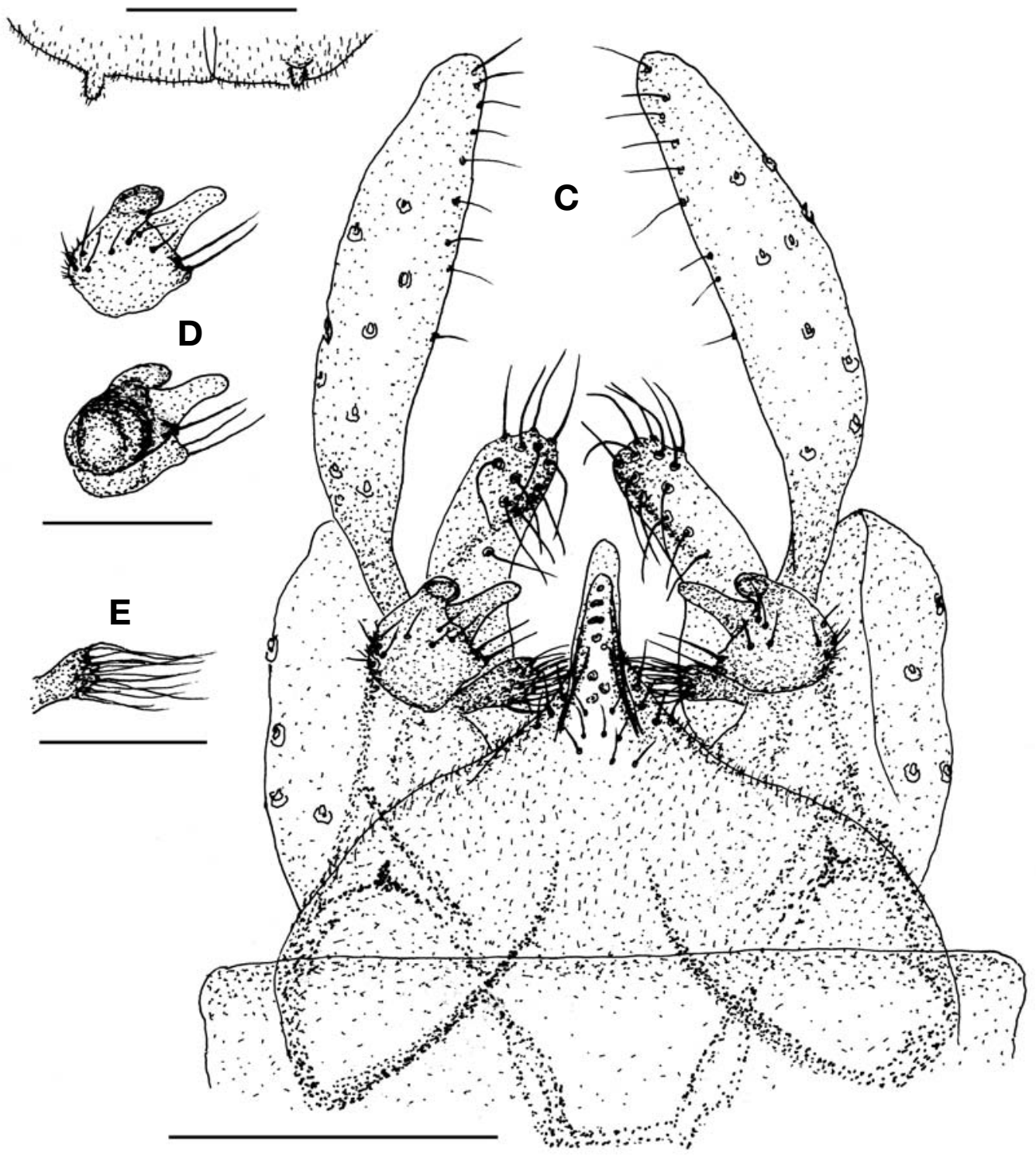

Fig. 8. Tanytarsus seohyoni n. sp. (Male). A, Wing; B, Frontal tubercle; C, Hypopygium; D, Dorsal (above) and ventral (below) view of superior volsalla; $E$, Median volsella. Scale bars $=0.5 \mathrm{~mm}(A), 0.1 \mathrm{~mm}(C), 0.05 \mathrm{~mm}(B, D, E)$.

9A): Wing length $2.2 \mathrm{~mm}$. Distal half of wing membrane with macrotrichiae. $\mathrm{R}_{1}, \mathrm{R}_{4+5}, \mathrm{M}_{1+2}, \mathrm{M}_{3+4}, \mathrm{Cu}_{1}$ setosed. Costa not extended. $\mathrm{R}_{2+3}$ running close to $\mathrm{R}_{4+5} \cdot \mathrm{R}_{2+3}$ ending in proximal $1 / 3$ between ends of $R_{1}$ and $R_{4+5}$. $R M$ proximal to 

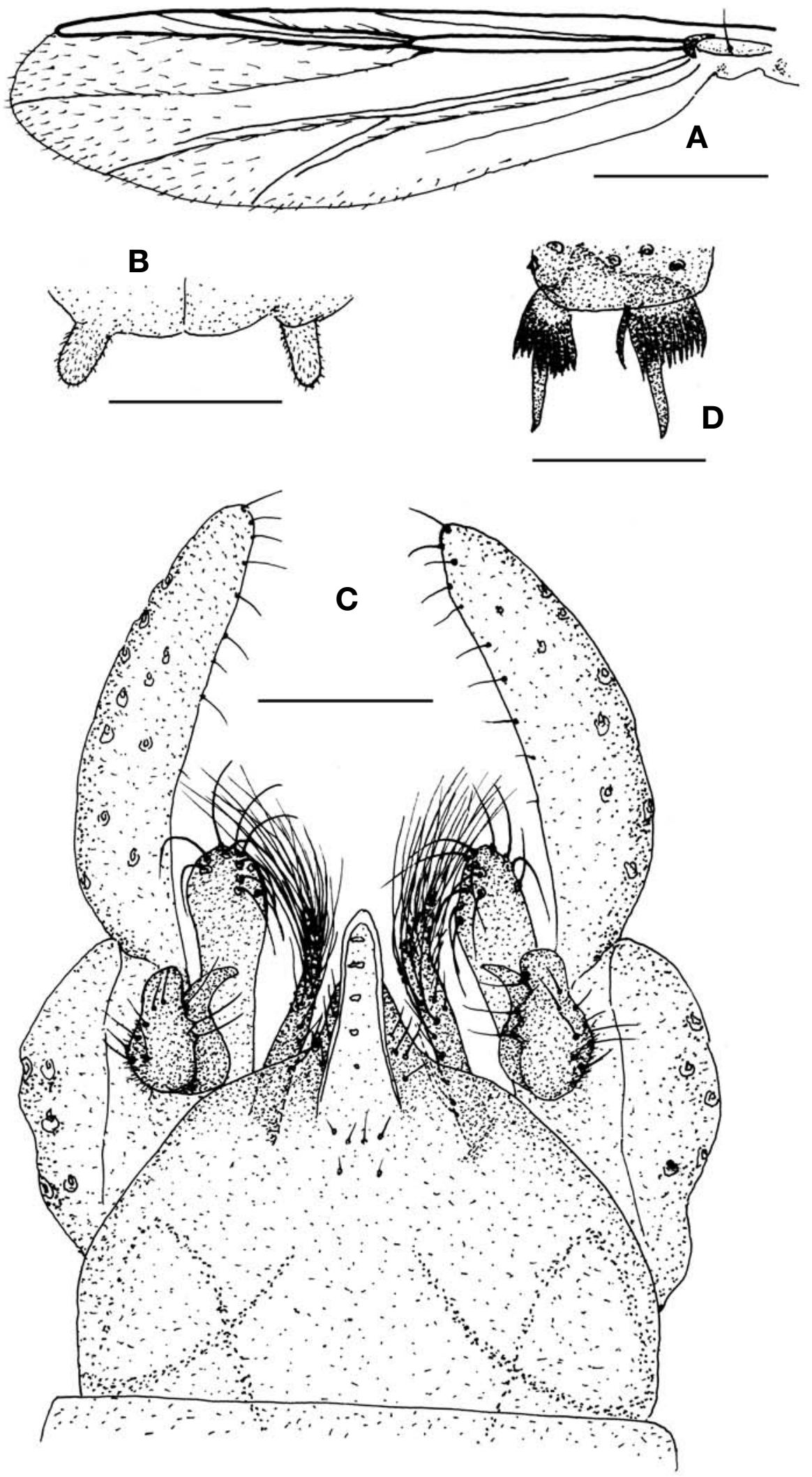

Fig. 9. Tanytarsus takahashii Kawai and Sasa, 1985 (Male). A, Wing; B, Frontal tubercle; C, Hypopygium; D, Comb scales of mid tibia. Scale bars $=0.5 \mathrm{~mm}(A), 0.05 \mathrm{~mm}(B-D)$. 

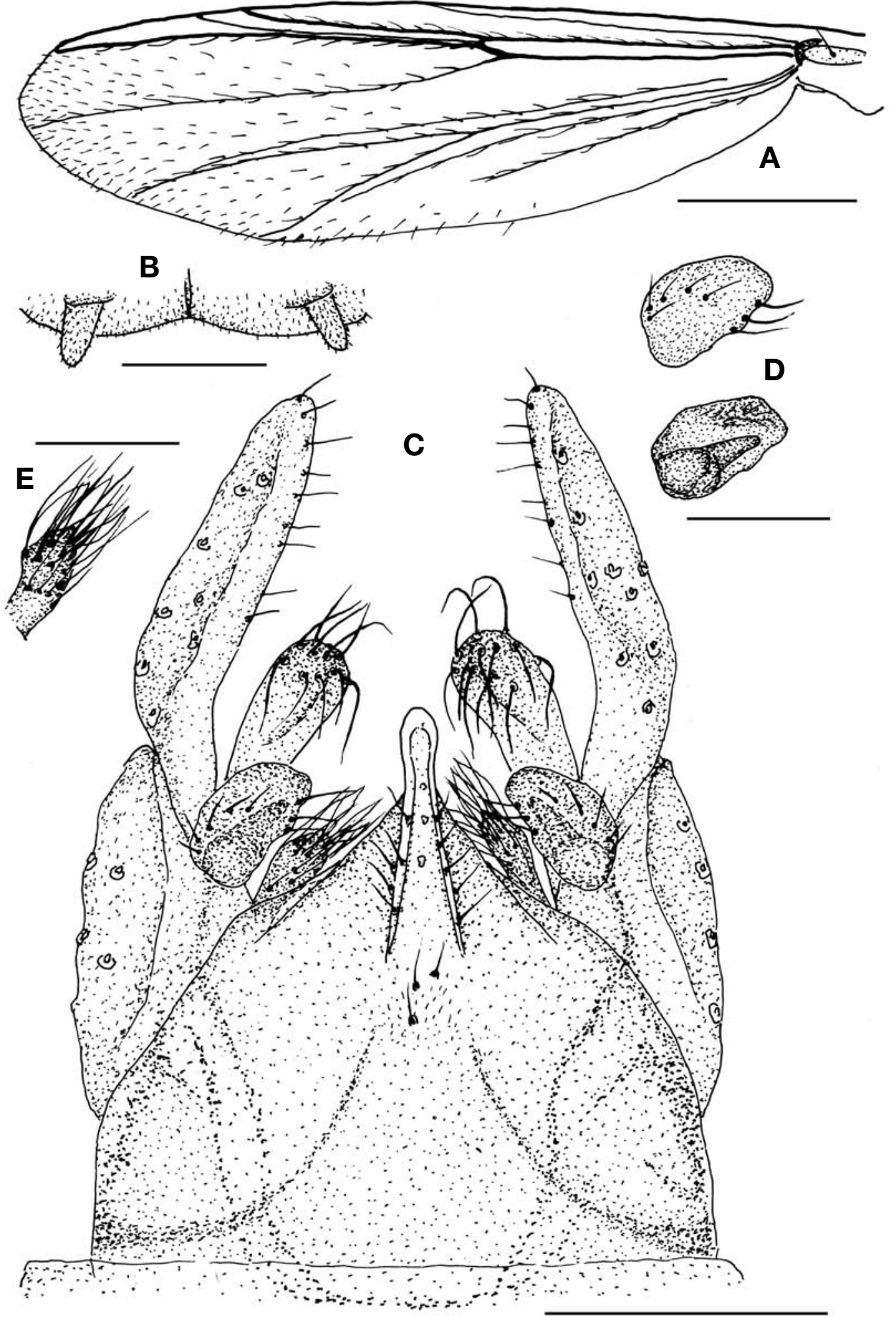

Fig. 10. Tanytarsus yoni n. sp. (Male). A, Wing; B, Frontal tubercle; $C$, Hypopygium; $D$, Dorsal (above) and ventral (below) view of superior volsella; $E$, Median volsella. Scale bars $=0.5 \mathrm{~mm}(A), 0.1 \mathrm{~mm}(C), 0.05 \mathrm{~mm}(B, D, E)$. 
FCu. Anal lobe not developed. Squama bare. Brachiolum with 1 seta. LEGS: Uniformly yellowish brown. Mid and hind tibial combs widely separated, each with a spur (Fig. 9D). Pulvillus absent. LR 2.63. ABDOMEN: Uniformly pale yellow. HYPOPYGIUM (Fig. 9C): Anal tergite produced posteriorly, with several minute setae each side of anal point, 6-7 minute setae on base of anal point. Anal point smoothly rounded at tip, with distinct crest and 4-5 poorly developed spines. Superior volsella somewhat oval in shape, slightly constricted at distal $1 / 3$, with 3 long setae on inner margin and 7-8 short setae dorsally and laterally; digitus distinct, separated from superior volsella. Median volsella very long, slightly curved outward, with numerous long simple setae, extending beyond of inferior volsella. Inferior volsella sylindrical, clubbed at tip with 9-11 setae. Gonostylus slightly tapered apically, with round tip, narrowed basally.

Remarks. The present Korean specimens are well coincided with Tanytarsus takahashii Kawai and Sasa in most morphological structures, with a minor difference in LR (2.63 in Korean species versus 3.18 in Ta. takahashii of Japan) (Kawai and Sasa, 1987).

\section{Genus Tanytarsus v.d. Wulp}

${ }^{1 *}$ Tanytarsus yoni sp. nov. (Fig. 10)

Material examined. Holotype: $1 \sigma^{\top}$ (CH-5786), Sinsau-dong, Chuncheon-si, Gangwon-do; 1 May 2009; K.Y. Jeong. Paratype: $10 \sigma^{7} \sigma^{7}(\mathrm{CH}-5805,5902,5976,5983,5988,6003,6006$, $6007,6041,6160), 3$ 우 우 (CH-5989, 6004, 6047), same as holotype.

Diagnosis. Yellowish, medium to small species. Wing length of male and female both $2.3 \mathrm{~mm}$. Superior volsella oval, inner margin more or less straight, with 5 dorsal setae and 3 inner marginal setae; digitus short, not reaching to margin of superior volsella. Median volsella short with 3-4 lamelated and many simple setae. 2 scutellars at middle. AR 1.1. LR 2.4. Description (Male). HEAD: Yellowish brown. Eye black, bare, moderately produced dorsomedially. Frontal tubercle (Fig. 10B) moderately developed ( $22 \mu \mathrm{m}$ long), widely separated each other. Antenna pale dark brown, with 13 segments, AR 1.1. Palp pale dark brown, with 5 segments: 45, 43, 129 , $154,236 \mu \mathrm{m}(1: 1.0: 2.9: 3.4: 5.3)$. 8-9 postoculars each side. Clypeus yellowish brown, with 14 setae. THORAX: Yellowish brown in ground color. Antepronotum yellowish brown, somewhat reduced, clearly separated medially. Scutum yellowish brown, with dark brown vittae, overreaching antepronotum; 9-11 acrosticals; 6-8 dorsocentrals and 1 prealar each side. Scutellum pale yellow, with 2 setae at middle. Postnotum dark brown. WING (Fig. 10A): Wing length $2.3 \mathrm{~mm}$. Distal half of membrane with macrotrichiae. Costa not produced. $\mathrm{R}_{2+3}$ weak, running close to $\mathrm{R}_{4+5}$, and ending in proximal $1 / 3$ between ends of $R_{1}$ and $R_{4+5} \cdot R_{4+5}$ ending distal to apex $\mathrm{M}_{3+4}$. RM proximal to $\mathrm{FCu}$. An reaching $\mathrm{FCu}$. Anal lobe not developed. Squama bare. Arculus dark brown, brachiolum pale dark brown, with one seta. LEGS: All segments pale dark brown; fore leg slightly darker. LR 2.4. Mid and hind tibial combs widely separated, each with a spur. Pulvillus absent. ABDOMEN: Uniformly pale, greenish yellow. HYPOPYGIUM (Fig. 10C): Anal tergite strongly produced posteriorly, with only 2-3 minute setae at base of anal point. Anal tergite band widely separated. Anal point remarkably immersed into anal tergite, apex round, with distinct crests and 3-5 weak, pale spine clusters; several minute setae along each side of anal point. Superior volsella (Fig. 10D) somewhat oval, inner margin more or less straight, with 5 dorsal setae and 3 inner marginal setae; digitus short, not reaching margin of superior volsella. Median volsella (Fig. 10E) short, with 3-4 lamelated and many simple setae. Inferior volsella sylindrical, slightly curved inward, with recurved apical setae. Gonostylus, slightly curved inward at base, with round tip. Female. Generally same as male, except usual sexual differences. Antenna pale dark brown, tip of last segment darker, with 4 segments (1st and 2nd segments fused): 125, 75, 86, $164 \mu \mathrm{m}$. Wing length $2.3 \mathrm{~mm}$.

Remarks. Tanytarsus yoni $\mathrm{n}$. sp. is very similar to Tanytarsus kiseogi $\mathrm{n}$. sp. in most structures; however the former is larger in body size (Wing length $2.3 \mathrm{~mm}$ vs $1.8 \mathrm{~mm}$ ), frontal tubercle of the former is also larger. Scutal vittae of the former is distinct dark brown, whereas that of the later is absent, and gonostylus of the former is slightly curved inward at base, whereas that of the later is almost straight.

Subfamily Orthocladiinae Edwards

Genus Cricotopus v.d. Wulp

${ }^{2 *}$ Cricotopus tricinctus (Meigen, 1818) (Fig. 11)

Chironomus tricinctus Meigen, 1818, p. 49

Cricotopus tricinctus: Tokunaga, 1936, p. 14; Sasa, 1981, p. 11; Sasa and Kawai, 1987, p. 41.

Material examined. 1 万๐ (CH-6001): Sinsau-dong, Chuncheonsi, Gangwon-do; 1 May 2009; K.Y. Jeong.

Diagnosis. Small to medium sized, dark brown species. Wing length $2.4 \mathrm{~mm}$. Abdominal tergites I, IV, VII pale, other tergite mostly black. Inner lobe of gonocoxite somewhat conical, with 6-7 dorsal sete and 5-6 ventral setae. Posterior margin of anal tergite bilobed. Anal point absent. AR 1.7. LR 0.6. Description (Male). HEAD: Eye pubescent, slightly produced dorsomedially. Frontal tubercle absent. Antenna dark

\footnotetext{
$1 *$ 연장부깔따구(신칭), ${ }^{2 *}$ 세 흰마디아기깔따구(신칭)
} 

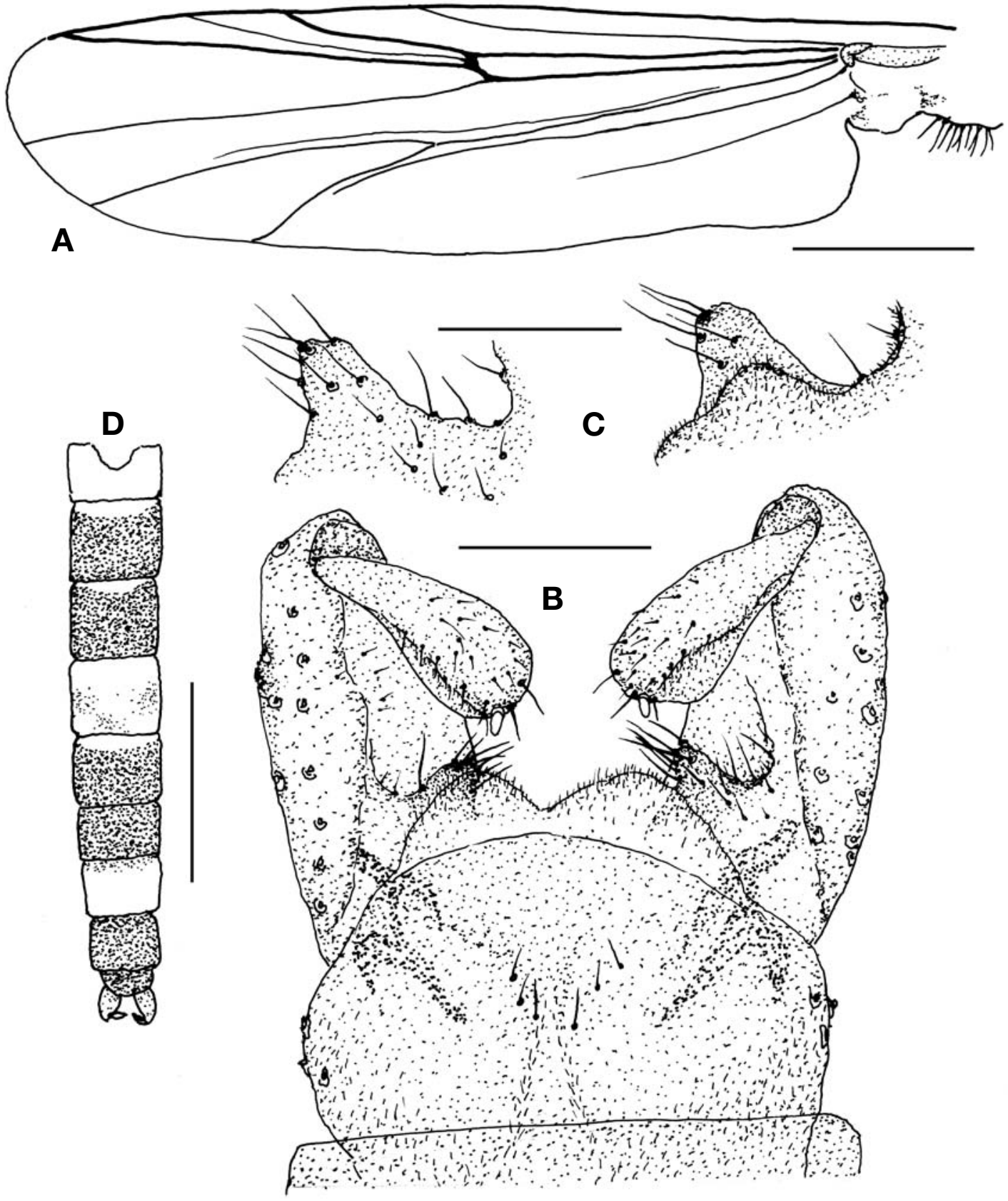

Fig. 11. Crictopus tricinctus (Meigen, 1818) (Male). A, Wing; B, Hypopygium; C, Inner lobe of gonocoxite (left dorsal, right ventral); $D$, Abdomen (dorsal). Scale bars $=0.5 \mathrm{~mm}(A), 0.1 \mathrm{~mm}(B), 0.05 \mathrm{~mm}(C), 1.0 \mathrm{~mm}(D)$.

brown, with 13 segments; AR 1.65. Clypeus dark brown, with 14 setae. Palp dark brown, with 4 segments; 71, 129, $143,186 \mu \mathrm{m}(1: 1.8: 2: 2.6)$. THORAX: ground color brownish yellow. Antepronotum well developed, brownish yellow, without seta. Scutum brownish yellow, with dark brown vittae; 21 minute acrosticals; 24-26 minute dorsocentrals each side. Scutellum dark brown, posterior margin yellowish, with 13 setae. Postnotum dark brown. WING (Fig. 11A): Wing length $2.4 \mathrm{~mm}$. Wing membrane bare. Only R setosed, all other veins bare. Costa slightly produced. $\mathrm{R}_{2+3}$ running mid of $R_{1}$ and $R_{4+5}$ and ending midway between ends of $R_{1}$ and $\mathrm{R}_{4+5}$. FCu distal to RM. An not reaching to $\mathrm{FCu}$. Anal lobe well developed. Squama fringed. LEGS: Fore coxa pale, mid and hind coxa brown. Proximal half of all femura yellowish brown, distal half dark brown. Fore tibia brown with proximal and distal ends dark brown; mid and hind tibiae pale, 

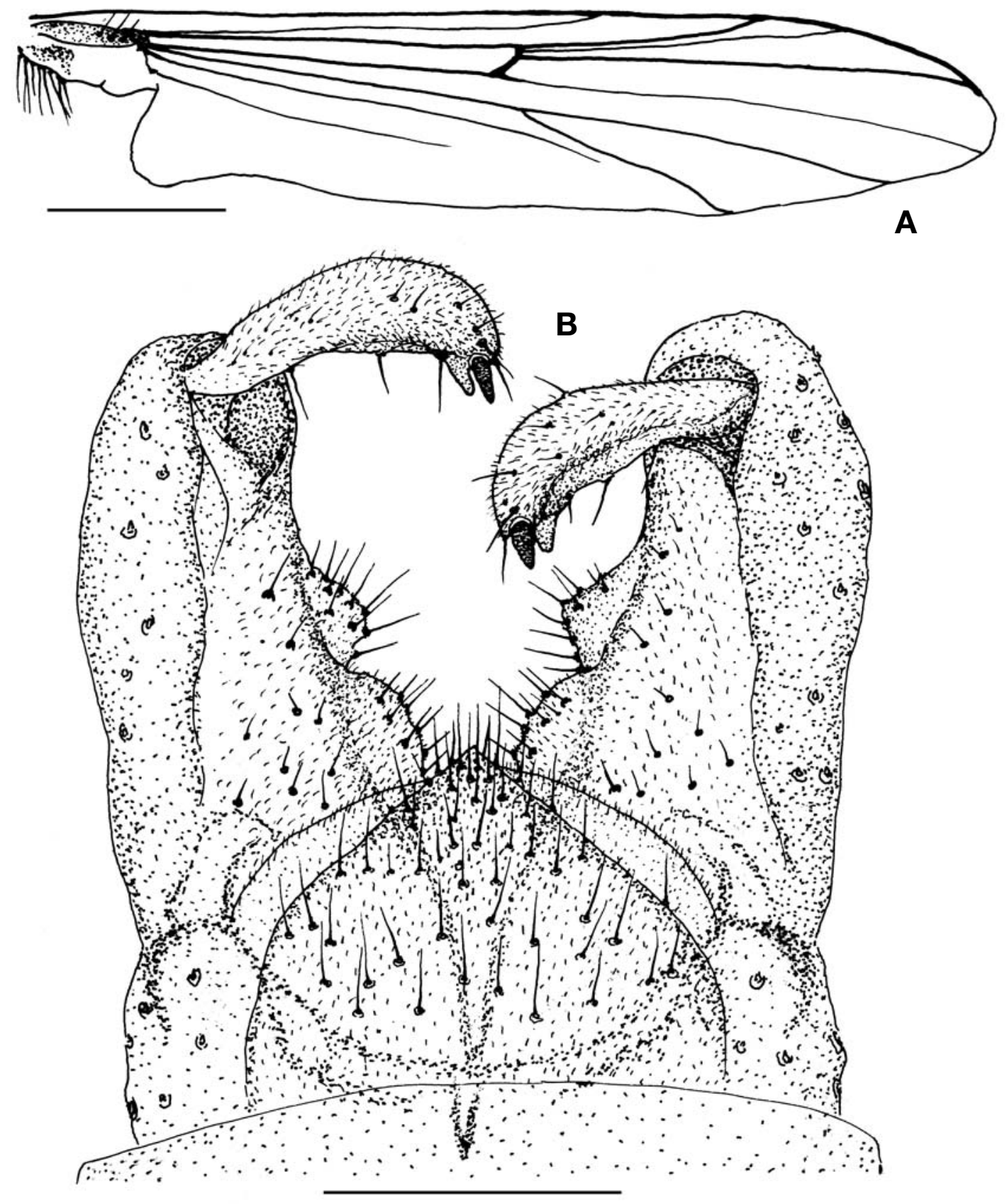

Fig. 12. Orthocladius seonwui n. sp. (Male). A, Wing; $B$, Hypopygium. Scale bars $=0.5 \mathrm{~mm}(\mathrm{~A}), 0.1 \mathrm{~mm}(\mathrm{~B})$.

with proximal and distal ends dark brown. Fore tarsi I-V dark brown; mid and hind tarsi I-II light brown, III-V dark brown. LR 0.6. ABDOMEN (Fig. 11D): Abdominal tergites, I, IV and VII pale yellow; tergites II, III, V and VI darkbrown, with a narrow pale band basally; tergites VIII and IX dark brown. HYPOPYGIUM (Fig. 11B): Posterior margin of 9th tergite bilobed. Anal point absent. Inner lobe of gonocoxite more or less conical, with 6-7 dorsal and 5-6 ventral setae
(Fig. 11C). Gonostylus stout, expanded distally, covered with microtrichae and many setae mostly on ventral side, with dark, stout, apical spine.

Remarks. Cricotopus tricinctus (Meigen) is very rare species in Korea, as only one specimen was collected for the first time in 2009. Most characters of the present specimen is well fit to $C r$. tricinct, except body size is much larger (Wing length $2.4 \mathrm{~mm}$ vs $1.7 \mathrm{~mm}$ ) (Sasa, 1981). 

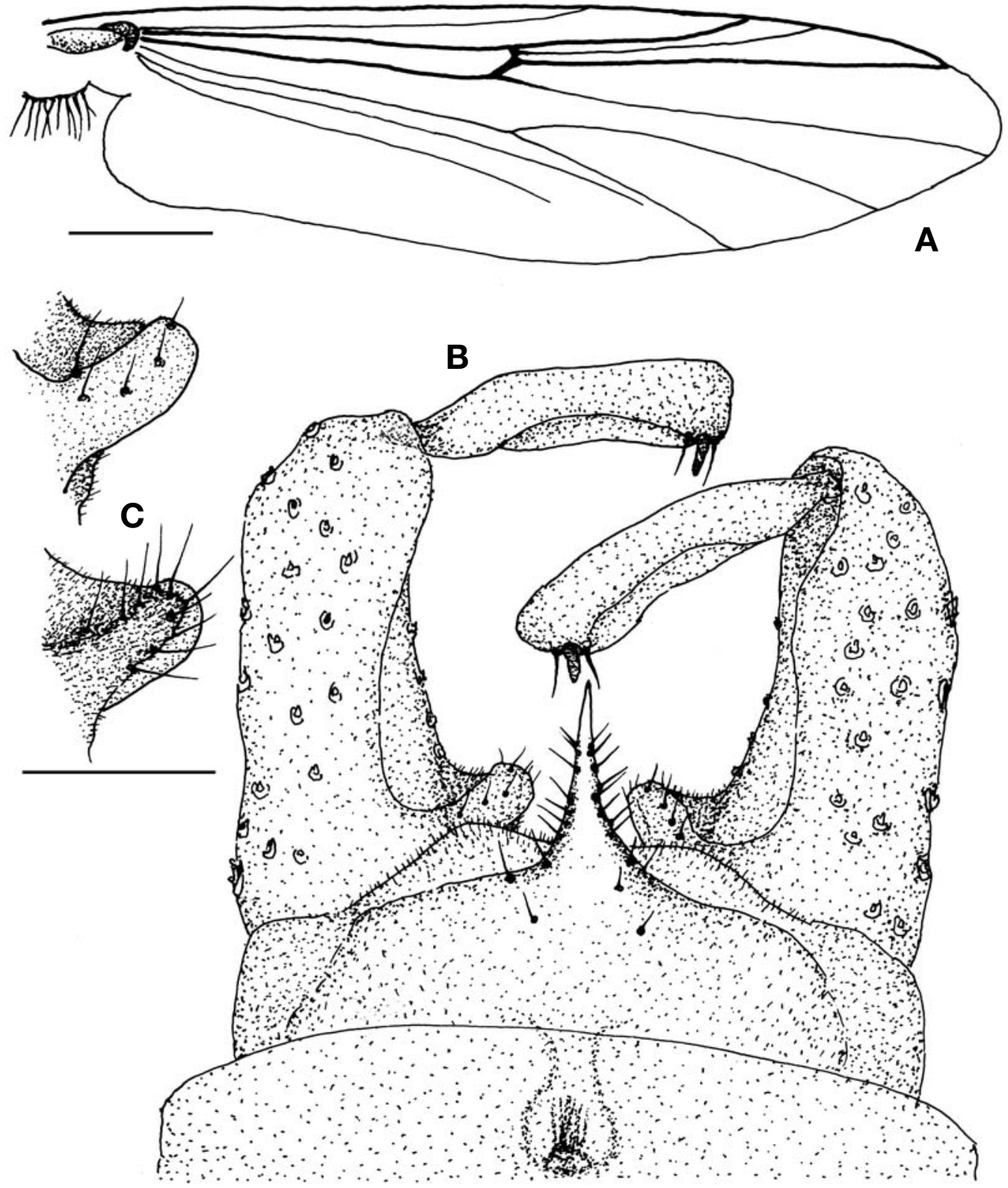

Fig. 13. Orthocladius yugashimaensis Sasa, 1979 (Male). A: Wing; B: Hypopygium; C: Dorsal (above) and Ventral (below) view of inner lobe of gonocoxite. Scale bars $=0.5 \mathrm{~mm}(A), 0.1 \mathrm{~mm}(B), 0.05 \mathrm{~mm}(C)$.

\section{Genus Orthocladius v.d. Wulp}

$1 *$ Orthocladies seonwui sp. nov. (Fig. 12)

Material examined. Holotype: $1 \sigma^{7}$ (CH-6141), Sinsau-dong, Chuncheon-si, Gangwon-do; 1 May 2009; K.Y. Jeong. Paratype: 5 万フ જ (CH-5823, 6142, 6149, 6150, 6151), data same as holotype.
Diagnosis. Small to medium sized, dark brown species. Wing length $2.4 \mathrm{~mm}$. Anal point small, triangular with many setae. Inner lobe of gonocoxite double: dorsal one at base and ventral one at middle, both with many setae. Gonostylus with an apical spine and a subapical lobe. AR 2.14. LR 0.75.

Description (Male). HEAD: Dark brown. Eye bare, slightly produced dorsomedially. Frontal tubercle absent. Antenna

1*선우깃깔따구(신칭) 
dark brown, with 13 flagellomeres; AR 2.14. Palp dark brown, with 4 segments: $79,127,111,166 \mu \mathrm{m}(1: 1.6: 1.4: 2.1)$. Clypeus with 17 setae. THORAX: Brown in ground color. Antepronotum dark brown, well developed, with 8 rather small setae on ventral side. Scutum dark brown, vittae absent; acrosticals absent; 11-12 dorsocentrals each side. Scutellum dark brown, with 10 setae. Postnotum dark brown. Halter dark brown. WING (Fig. 12A): Wing length 2.4 mm. Membrane bare. Costa slightly produced. $\mathrm{R}_{2+3}$ ending proximal $1 / 3$ between $R_{1}$ and $R_{4+5}$. Only vein $R$ setosed. $R_{4+5}$ ending distal to end of $\mathrm{M}_{3+4}$. FCu oposite of RM. $\mathrm{Cu}_{1}$ almost straight. Anal lobe well developed. Squama setosed. Archlus dark brown; brachiolum dark brown, with 3 minute setae. LEGS: Uniformly dark brown. Fore tibia with a long, narrow spine apically; mid tibia with 2 subequal spines; hind tibia with a long spine and 11-12 free spinules. Mid and hind tarsus I with a pseudospur. Pulvillus absent. LR 0.75. ABDOMEN: Uniformly dark brown. HYPOPYGIUM (Fig. 12B): Anal point broad, tapered posteriorly (triangular in shape), with numerous setae. Inner margin of gonocoxite produced into 2 separate lobes: dorsal lobe smoothly round at base of gonocoxite, and ventral lobe triangular at middle of gonocoxite, both lobes with many setae. Gonostylus somewhat broadened distally, with a distinct apical spine and a subapical lobe ventrally.

Remarks. This new species belongs to the genus Orthocladius, as pulvillus absent, squama fringed and anal point present, and belongs to subgenus Pogonocladius as gonoxocite well developed and anal lobe of wing strongly produced (Cranston et al., 1989). Anal point of Orthocladius seonwui n. sp. is rather unique, which is not commonly found in the genus Orthocladius.

Genus Orthocladius v.d. Wulp

$1 *$ Orthocladius yugashimaensis Sasa, 1979 (Fig. 13)

Orthocladius yugashimuensis Sasa, 1979, p. 23; Sasa, 1981, p. 84

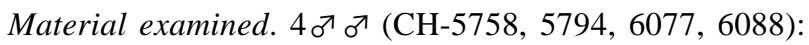
Sinsau-dong, Chuncheon-si, Gangwon-do; 1 May 2009; K.Y. Jeong.

Diagnosis. Medium sized, dark brown midge. Wing length $3.1 \mathrm{~mm}$. Anal point pale, sharply pointed, with 8-10 lateral setae each side. Two inner lobes of gonocoxite overlapped: dorsal lobe roughly rectiangular with 4 short setae, and ventral lobe triangular with several moderately long setae. AR 2.3. LR 0.8.

Description (Male). HEAD: Dark brown. Eye black, bare, with dorsomedial projection. Frontal tubercle absent. Antenna dark brown, with 13 segments, AR 2.3. Palp dark brown, with 4 segments: $79,191,180,241 \mu \mathrm{m}(1: 2.4: 2.3: 3.1)$. Clypeus dark brown, roughly rectangular, with 21 setae. THORAX: Yellowish brown in ground color. Antepronotum dark brown, well developed, with 4-5 setae ventrally. Scutum dark brown, vittae inconspicunous; 11 acrosticals, 9-11 dorsocentrals each side. Scutellum dark brown, with 10-13 setae. Postnotum dark brown. Halter yellowish brown. WING (Fig. 13A): Wing length $3.1 \mathrm{~mm}$. Wing membrane bare. All veins bare, except basal half of $\mathrm{R}$ with several minute setae. Costa not produced. $\mathrm{R}_{2+3}$ ending about proximal $1 / 3$ between ends of $\mathrm{R}_{1}$ and $\mathrm{R}_{4+5}$. FCu under RM. $\mathrm{Cu}_{1}$ almost straight. Anal lobe developed. Squama fringed. LEGS: All segments uniformly dark brown. Fore tibia with a long apical spine; mid tibia with 2 short apical spines; hind tibia with a long spine, a short spine and 12-14 free comb spines. Mid tarsi I-II and hind tarsus I with 2 short pseudospines. Pulvillus absent. LR 0.8. ABDOMEN: All tergites uniformly pale dark brown. HYPOPYGIUM(Fig. 14B): Anal point pale, sharply pointed, with 8-10 setae on each lateral side. Anal tergite with only 5-7 short setae near base of anal point. Dorsal lobe of gonocoxite roughly rectangular in form, with 4 short setae and ventral lobe of gonocoxite triangular in form with several long setae (Fig. 13C). Gonocoxite rather long, paralled-sided. Gonostylus slightly expanded apically, with a strong, short, apical spine.

Remarks. The present four male specimens collected in May 2009 are well coincided with Orthocladius yugashimaensis reported in Japan in general structures (Sasa, 1979), except several minor differences including body size. The Korean specimens are larger (Wing length $3.1 \mathrm{~mm}$ ) than Japanese specimens (Wing length 2.6-2.8 mm). Hundreds of adults of this species attracted to light on 13th floor apartment were collected at Jungye-dong, Nowon-gu, Seoul on 23 February 2010. This apartment is located near Danghyun stream, a tributary of Han river.

2*Genus Parakiefferiella Thienemann

$3 *$ Parakiefferiella bathophila (Kieffer, 1912) (Fig. 14)

Dactylocladius bathophila Kieffer, 1912, p. 88.

Eukiefferiella (Parakiefferiella) bathophyla: Goetghebuer, 1950, p. 123.

Parakiefferiella bathophyla: Brundin, 1956, p. 148; Pinder, 1978, p. 92; Sasa, 1985, p. 60; Sasa, 1989, p. 67; Sasa and Kondo, 1991, p. 103.

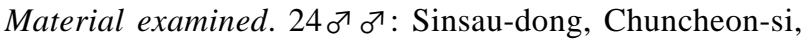
Gangwon-do; 14 Sept. 2008; K.Y. Jeong; 17 ð Љ : Locality same; 1 May 2009; K.Y. Jeong.

\footnotetext{
${ }^{1 *}$ 유가시마깃깔따구(신칭), ${ }^{2 *}$ 숲깔따구속(신칭), ${ }^{3 *}$ 삼지창숲깔따구(신칭)
} 

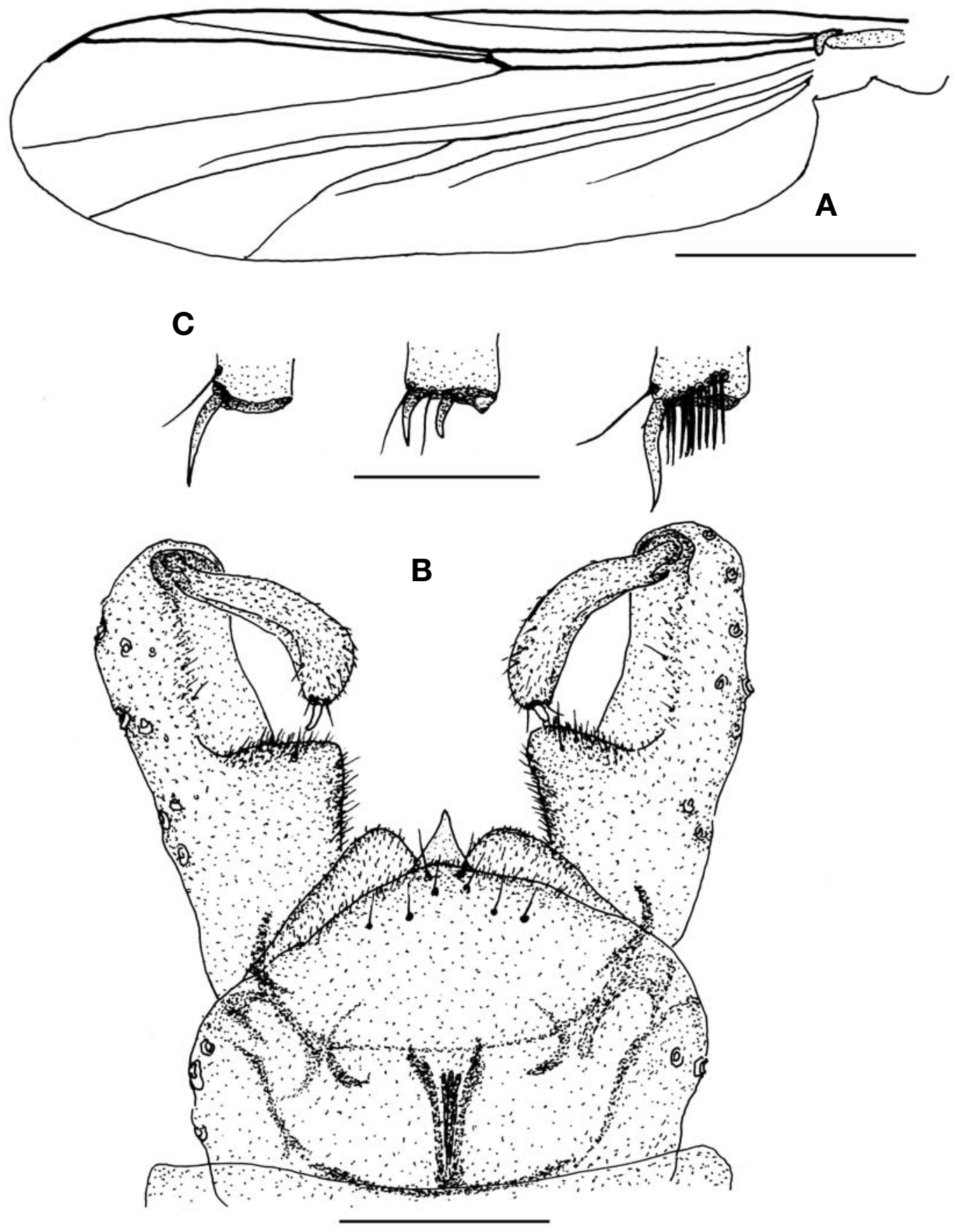

Fig. 14. Parakiefferiella bathophila (Kieffer, 1912) (Male). A, Wing; B, Hypopygium; C, Apical spines of tibia (fore, mid and hind, from left). Scale bars $=0.5 \mathrm{~mm}(A), 0.05 \mathrm{~mm}(B, C)$.

Diagnosis. Rather small, yellowish brown species. Wing length $1.2 \mathrm{~mm}$. Anal point short, triangular. Anal tergite with strong, trident virga. Inferior volsella large, roughly triangular, with numerous minute setae. Gonostylus curved inward. AR 0.8. LR 0.5.

Description (Male). HEAD: Yellowish brown. Eye reniform, bare, not produced dorsomedially. Antenna yellowish brown, with 13 segments, AR 0.8. 3-4 postoculars each side. Palp pale brown, with 5 segments: $20,36,62,68,89 \mu \mathrm{m}(1: 1.8$ : $3.1: 3.4: 4.5$ ). Clypeus roughly rectangular, yellowish brown, with 4-6 setae. THORAX: Yellowish dark brown in ground color. Antepronotum yellowish brown, moderately develop- 

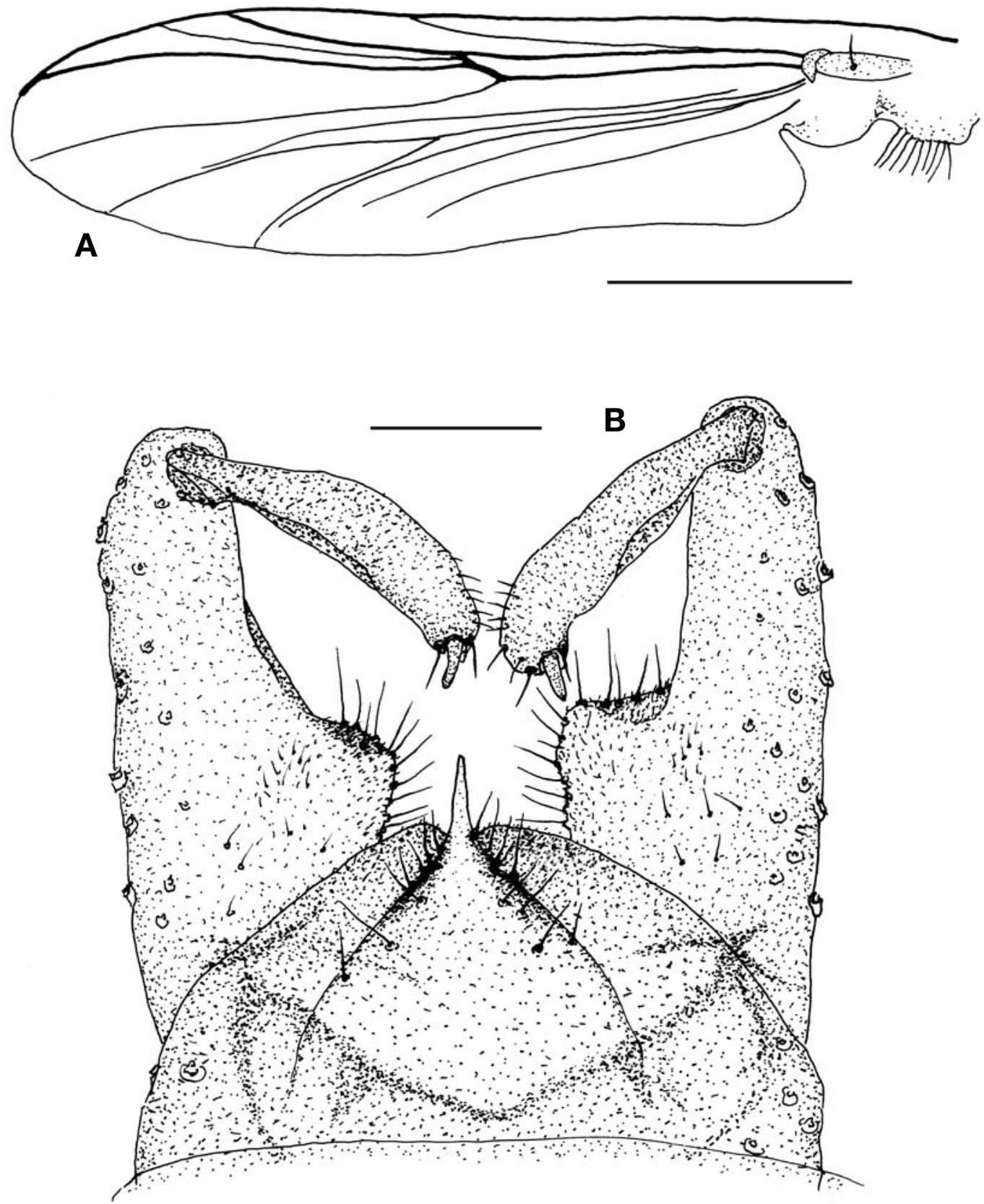

Fig. 15. Psectrocladius kangi n. sp. (Male). A, Wing; B, Hypopygium. Scale bars $=0.5 \mathrm{~mm}(\mathrm{~A}), 0.05 \mathrm{~mm}(\mathrm{~B})$.

ed. Scutum brown, with inconspicuous vittae; acrosticlas absent; 4-6 dorsocentrals each side. Scutellum yellowish brown, with 2 setae. Postnotum dark brown. WING (Fig. 14A): Wing length $1.2 \mathrm{~mm}$. Membrane bare. Costa distinctly extended. $\mathrm{R}_{2+3}$ ending to about middle of $\mathrm{R}_{1}$ and $\mathrm{R}_{4+5}$. $\mathrm{R}_{4+5}$ ending oppsite end of $\mathrm{M}_{3+4}$. $\mathrm{Cu}_{1}$ gently curved at middle. $\mathrm{FCu}$ distal to $\mathrm{RM}$. An extending to $\mathrm{FCu}$. Anal lobe poorly developed. Squama bare. LEGS: Uniformly yellowish pale brown. Frontal tibia with a long, apical spur; mid tibia with 2 short spurs apically; hind tibia with a long spur and free comb spurs (Fig. 14C). Pulvillus absent. LR 0.5. ABDOMEN: All segments uniformly yellowish pale brown, 6th-8th tergites slightly darker. HYPOPYGIUM(Fig. 14B): Anal point short, triangular. Anal tergite with 6-9 rather short setae around base of anal point; verga strong, trident form. Inner lobe of gonocoxite (inferior volsella) large, roughly triangular, with 
numerous minute setae. Gonostylus curved inward, with apical spur and 2 apical setae.

Remarks. Among the known species of the genus Parakiefferiela, the present specimens are well coincided to $P a$. bathophila, except that AR of Korean specimens was 1.5, whereas that of Japanese specimens 0.8-0.9, and Korean specimens are smaller in body size, i.e. $1.2 \mathrm{~mm}$ vs $1.4-1.5 \mathrm{~mm}$ in wing length (Sasa, 1985). However these differences of AR and body size would be readily treated as the geographical variation. The genus Parakiefferiela is the new findings in Korea.

\section{$1 *$ Genus Psectrocladius Kieffer \\ $2 *$ Psectrocladius kangi sp. nov. (Fig. 15)}

Material examined. Holotype: $1 \sigma^{\nearrow}(\mathrm{CH}-4808)$, Sinsau-dong, Chuncheon-si, Gangwon-do; 1 Aug. 2008; K.Y. Jeong. Paratype: 2 ð ๙ (CH-4786, 5830), same as holotype (CH-5830 collected on 14 Sept. 2008).

Diagnosis. Small, yellowish brown midge. Wing length 1.6 $\mathrm{mm}$. Wing veins pale, weakly developed, without setae. Anal point narrow, tapered posteriorly. Inner lobe of gonocoxite somewhat triangular, with many setae along inner margin. AR 1.5. LR 0.72.

Description (Male). HEAD: Brownish yellow. Eye dark brown, bare, wedge-shaped, without dorsomedial extension. Frontal tubercle absent. Antenna yellowish dark brown, with 13 segments; AR 1.5. Clypeus brownish yellow, with 11-12 setae. Palp dark brown, with 4 segments: 43, 96, 107, 136 $\mu \mathrm{m}$ $(1: 2.2: 2.5: 3.2)$. THORAX: Yellow in ground color. Antepronotum yellow, moderately developed, lobes meeting at point anterior to scutal projection, with 4-5 setae on posterior margin. Scutum yellow, with dark brown vittae; acrosticals absent, 9-10 dorsocentrals and 2-4 prealars each side. Scutellum brownish yellow, with 5-6 scutellars. Postnotum dark brown. Halter yellowish brown. WING (Fig. 15A): Wing length $1.6 \mathrm{~mm}$. Membrane bare. All veins pale, weakly developed, without setae. Costa slightly extended. $\mathrm{R}_{2+3}$ running mid way between $R_{1}$ and $R_{4+5}$, ending closer to $R_{1}$ than to $\mathrm{R}_{4+5}$. $\mathrm{R}_{4+5}$ ending slightly distal to end of $\mathrm{M}_{3+4}$. $\mathrm{FCu}$ distal to RM. An distal to FCu. Anal lobe well developed. Squama fringed. Arculus pale, blachiolum pale, with 1 seta. LEGS: Fore leg pale dark brown, mid and hind legs pale, brownish yellow, with tarsi slightly darker. Fore tibia with a long spur; mid tibia with a rather strong, darkened spur; hind tibia with a long spur and free comb spurs. Mid tarsi I and II with 2 pseudospurs, hind tarsi I and II with a pseudospur. Pulvillus well developed. LR 0.72. ABDOMEN: Uniformly pale dark brown. HYPOPYGIUM (Fig. 15B): Anal point narrow, tapered posteriorly; base of anal point triangular with 5-6 setae each side. Gonocoxite well developed, inner lobe (inferior volsella) somewhat triangular, with many setae along inner margin. Gonostylus almost straight internally, with moderately developed apical spur (megaseta).

Remarks. This new species is closely related to Psectrocladius aquatronus Sasa reported in Japan (Sasa, 1979). However it differs in having smaller body size (1.6 mm versus $2.3-3.2$ $\mathrm{mm}$ of wing length), shorter AR (1.5 vs 1.7-2.1), and the different shape of gonostylus. The gonostylus of the former is almost parallel-sided, scaresely expanded apically, whereas that of the later is Chinese spoon-shaped, prominently expanded towards apex. The genus Psectrocladius is the first report in Korea.

3*Subfamily Prodiamesinae Saether

${ }^{4 *}$ Genus Monodiamesa Kieffer

${ }^{5 *}$ Monodiamesa bathyphila (Kieffer, 1918) (Fig. 16)

Prodiamesa (Monodiamesa) bathyphila Kieffer, 1918, p. 7; Tokunaga, 1936, p. 527.

Monodiamesa bathyphila: Pinder, 1978, p. 45; Sasa and Kawai, 1987, p. 54.

Material examined. 9 ఠ ○ (CH-5756, 5812, 6054, 6082, 6083, 6085, 6092, 6096, 6100), 1 우 (CH-6079): Sinsau-dong, Chuncheon-si, Gangwon-do; 1 May 2009; K.Y. Jeong.

Diagnosis. Dark brown, large sized species. Wing length $3.7 \mathrm{~mm}$ in male, $4.4 \mathrm{~mm}$ in female. Cross vein $\mathrm{MCu}$ proximal to $\mathrm{FCu}$. Anal point narrow, with a short seta at tip. Gonocoxite with 2 large inner lobes, overlapped each other: dorsal one larger, with numerous short setae, ventral one narrower covered with microtrichiae. A pair of long sharp spines at ventral base of gonocoxite. AR 2.3. LR 0.91.

Description (Male). HEAD: Brown. Eye dark brown, bare, produced dorsomedially. 2-3 orbitals, 7-9 postoculars. Frontal tubercle absent. Antenna dark brown, with 13 segments, AR 2.3. Palp dark brown, with 4 segments: 108, 187, 187, 216 $\mu \mathrm{m}(1: 1.7: 1.7: 2.0)$. Clypeus dark brown, somewhat square in shape, with 11 setae. THORAX: Dark brown. Antepronotum large, dark-brown, with 6-8 lateral setae, joined anterior to scutal projection. Scutum dark brown, vittae indistinct; acroscticals absent, 9-13 dorsocentrals and 6-7 prealars each side. Scutellum dark brown, with 23 setae. Postnotum dark brown. Halter yellowish brown. WING (Fig. 16A): Wing length $3.7 \mathrm{~mm}$. Membrane bare, with fine punctuation. Costa moderately extended. $\mathrm{R}_{2+3}$ ending about middle between ends of $\mathrm{R}_{1}$ and $\mathrm{R}_{4+5}$. FCu opposite to $\mathrm{RM}$. MCu proximal to $\mathrm{FCu}$. $\mathrm{Cu}_{1}$ slightly curved apically. Vein $\mathrm{R}$ only setose, all other veins bare. Brachiolum with 3 setae. Anal lobe developed. Squama fringed. LEGS: Uniformly dark brown. Fore

\footnotetext{
$1 *$ 풀깔따구속(신칭), ${ }^{2 *}$ 강풀깔따구(신칭), ${ }^{3 *}$ 전멧깔따구아과 (신칭), ${ }^{4 *}$ 단멧깔따구속(신칭), ${ }^{5 *}$ 쌍뿔단멧 깔따구(신칭)
} 

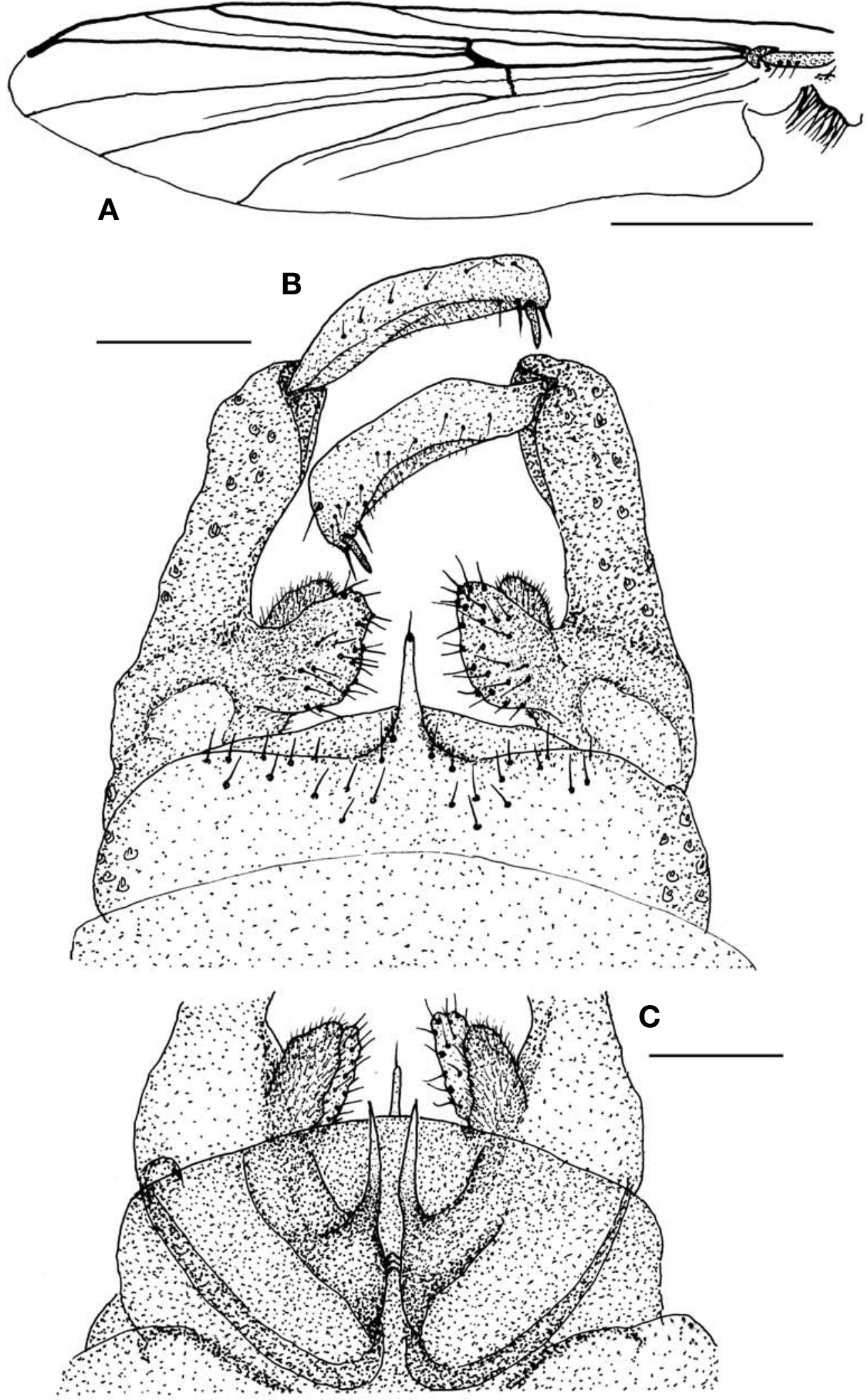

Fig. 16. Monodiamesa bathyphila (Kieffer, 1918) (Male). A, Wing; $B$, Hypopygium; C, Part of hypopygium (ventral). Scale bars=1.0 $\mathrm{mm}(A), 0.1 \mathrm{~mm}(B, C)$. 
tibia with a long spine at tip. Mid tibia with 2 spines of equal length; hind tibia with subequal 2 spines and 11-14 free comb spines; hind tarsi I and II with 2 pseudspines, respectively. Pulvillus absent. LR 0.91. ABDOMEN: All segments uniformly dark brown. HYPOPYGIUM (Fig. 16B): Anal tergite with many small setae posteriorly. Anal point narrow, with a short seta at tip. Gonocoxite with 2 large inner lobes, overlapped each other: dorsal lobe larger and wider with numerous short setae, ventral lobe narrower covered with microtrichiae. A pair of long sharp spines at ventral base of gonocoxite (Fig. 16C). Gonostylus paralled-sided, with a strong apical spine.

Female. Same as in male, except usual sexual differences. Antenna dark brown, with 6 segments: 98, 46, 64, 75, 89, $243 \mu \mathrm{m}$. Wing length $4.4 \mathrm{~mm}$.

Remarks. The subfamily Prodiamesinae, in which the genus Monodiamesa belongs is the first record from the Korean fauna. Morphological structures of Korean specimens are well coincided with those of European species (Pinder, 1978) and of Japanese ones (Tokunag, 1936; Sasa and Kawai, 1987). Only, a terninal seta on anal point is absent in Japanese bathyphila whereas it presents in European and Korean bathyphila.

\section{ACKNOWLEDGEMENTS}

This study was supported by the fund for "Arthropods of Medical Importance Resource Bank, Korea”.

\section{REFERENCES}

Cranston, P.S., D.R. Oliver and O.A. Saether, 1989. The adult males of Orthocladiinae of the Holarctic region-keys and diagnoses. Ent. Scand., 34(Suppl.): 165-352.

Cranston, P.S., M.E. Dillon, L.C.V. Pinder and F. Reiss, 1989. The adult males of Chironominae (Diptera, Chironomidae) of the Holarctic region-keys and diagnoses. Ent. Scand., 34(Suppl.): 353-502.

Edwards, F.W., 1929. British non-biting midges (Diptera, Insecta). Trans. R. ent. Soc. London, 77: 279-429.

Jeong, K.Y., H.Y. Yum, I.Y. Lee, H.I. Ree, C.S. Hong, D.S. Kim and T.S. Yong, 2004. Molecular cloning and characterization of tropomyosin, a major allergen of Chironomus kiiensis, a dominant species of nonbiting midges in Korea. Clin. Diagn. Lab. Immunol., 11: 320-324.

Kawai, K. and M. Sasa, 1985. Seven new species of chironomid midges (Diptera, Chironomidae) from the Ohta river, Japan. Jap. J. Limnol., 46: 15-24.
Kay, A.B., E.L. Gad, M.O. Rab, J. Stewart and H.H. Erwa, 1978. Widespread IgE-mediated hypersensitivity in Northern Sudan to the chironomid Cladotanytarsus lewisi. Clin. Exp. Immunol., 34: 106-110.

Na, K.B., 2004. Taxonomy of the Chironomidae (Diptera, Insecta) in Seoul-Gyeonggi area, Korea. M. Sc. Thesis. Seoul Women's University.

Pinder, L.C.V., 1978. A key to adult males of British Chironomidae. Freshwater Biol. Asso. Scie. Publ., 37: 1-169.

Ree, H.I., 2009a. One new and six unrecorded species of chironomidae (Insecta, Diptera) in Korea. Korean J. Syst. Zool., 25: 49-59.

Ree, H.I., 2009b. Three new and four unrecorded species of Chironomidae (Insecta, Diptera) in Korea. Korean J. Syst. Zool., 25: 243-254.

Ree, H.I. and H.S. Kim, 1981. Studies on Chironomidae (Diptera) in Korea. 1. Taxonomical study on adults of Chironomidae. Proc. Coll. Nat. Sci., SNU, 6: 123-226.

Ree, H.I. and J.H. Yum, 2006. Redescription of Chironomus salinarius (Diptera: Chironomidae), nuisance midges that emerged in brackish water of Jinhae-man (Bay), Kyongsangnam-do, Korea. Korean J. Parasitol., 2006; 44: 63-66.

Sasa, M., 1979. A morphological study of adults and immature stages of 20 Japanese species of the family Chironomidae (Diptera). Res. Rep. NIES, 7: 1-148.

Sasa, M., 1981. Studies on chironomid midges of the Tama river. Part 3. Species of the subfamily Orthocladiinae recorded at the summer survey and their distribution in relation to the pollution with sewage waters. Res. Rep. NIES, 29: 1-77.

Sasa, M., 1983. Studies on chironomid midges of the Tama reiver. Part 5. An observation on the distribution of Chironominae along the main stream in June, with description of 15 new species. Res. Rep. NIES, 43: 1-67.

Sasa, M., 1984. Studies on Chironomid midges in Lakes of the Nikko National Park. Part II. Taxonomical and morphological studies on the chironomid species collected from Lakes in the Nikko National Park. Res. Rep. NIES, 70: 19-215.

Sasa, M., 1985. Studies on chironomid midges of some lakes in Japan. Res. Rep. NIES, 83: 1-160.

Sasa, M. and K. Kamimura, 1987. Chironomid midges collected on the shore of lakes in the Akan National Park, Hokkaido (Diptera, Chironomidae). Res. Rep. NIES, 104: 9-61.

Sasa, M. and K. Kawai, 1987. Studies on the chironomid midges of Lake Biwa (Diptera, Chironomidae). Lake Biwa Study Monog., 3: 1-119.

Sasa, M. and M. Kikuchi, 1995. Chironomidae (Diptera) of Japan. University of Tokyo Press, Tokyo, pp. 333.

Takunaga, M., 1936. Chironomidae from Japan (Diptera). VI Diamesinae. Philippine J. Scie., 59: 525-552. 